Article

\title{
Assessing Urban Vulnerability to Flooding: A Framework to Measure Resilience Using Remote Sensing Approaches
}

\author{
Mercio Cerbaro $^{1, *(\mathbb{D}}$, Stephen Morse ${ }^{1}(\mathbb{D})$, Richard Murphy ${ }^{1}\left(\mathbb{D}\right.$, Sarah $_{\text {Middlemiss }}{ }^{2}$ and Dimitrios Michelakis ${ }^{2}$ \\ 1 Centre for Environment \& Sustainability, University of Surrey, Guildford GU2 7XH, UK; \\ s.morse@surrey.ac.uk (S.M.); rj.murphy@surrey.ac.uk (R.M.) \\ 2 Ecometrica Limited, Orchard Brae House, 30 Queensferry Road, Edinburgh EH4 2HS, UK; \\ sarah.middlemiss@ecometrica.com (S.M.); dimitrios.michelakis@ecometrica.com (D.M.) \\ * Correspondence: m.cerbaro@surrey.ac.uk
}

Citation: Cerbaro, M.; Morse, S.; Murphy, R.; Middlemiss, S.; Michelakis, D. Assessing Urban Vulnerability to Flooding: A Framework to Measure Resilience Using Remote Sensing Approaches. Sustainability 2022, 14, 2276. https:// doi.org/10.3390/su14042276

Academic Editor: Michalis Diakakis

Received: 21 December 2021

Accepted: 11 February 2022

Published: 17 February 2022

Publisher's Note: MDPI stays neutral with regard to jurisdictional claims in published maps and institutional affiliations.

Copyright: (c) 2022 by the authors. Licensee MDPI, Basel, Switzerland. This article is an open access article distributed under the terms and conditions of the Creative Commons Attribution (CC BY) license (https:// creativecommons.org/licenses/by/ $4.0 /)$.

\begin{abstract}
Assessing and measuring urban vulnerability resilience is a challenging task if the right type of information is not readily available. In this context, remote sensing and Earth Observation (EO) approaches can help to monitor damages and local conditions before and after extreme weather events, such as flooding. Recently, the increasing availability of Google Street View (GSV) coverage offers additional potential ways to assess the vulnerability and resilience to such events. GSV is available at no cost, is easy to use, and is available for an increasing number of locations. This exploratory research focuses on the use of GSV and EO data to assess exposure, sensitivity, and adaptation to flooding in urban areas in the cities of Belem and Rio Branco in the Amazon region of Brazil. We present a Visual Indicator Framework for Resilience (VIFOR) to measure 45 indicators for these characteristics in $1 \mathrm{~km}^{2}$ sample areas in poor and richer districts in the two cities. The aim was to assess critically the extent to which GSV-derived information could be reliable in measuring the proposed indicators and how this new methodology could be used to measure vulnerability and resilience where official census data and statistics are not readily available. Our results show that variation in vulnerability and resilience between the rich and poor areas in both cities could be demonstrated through calibration of the chosen indicators using GSV-derived data, suggesting that this is a useful, complementary and cost-effective addition to census data and/or recent high resolution EO data. Furthermore, the GSV-linked approach used here may assist users who lack the technical skills to process raw EO data into usable information. The ready availability of insights on the vulnerability and resilience of diverse urban areas by straightforward remote sensing methods such as those developed here with GSV can provide valuable evidence for decisions on critical infrastructure investments in areas with low capacity to cope with flooding.
\end{abstract}

Keywords: vulnerability; flooding; remote sensing; Earth Observation (EO); Google Street View (GSV); climate change

\section{Introduction}

Floods are one of the most common and severe hazards to disrupt people's livelihoods globally [1]. The effects of climate change and widespread flooding can exacerbate urban challenges and make it more difficult to tackle issues and help vulnerable communities in informal settlements [2]. The Intergovernmental Panel on Climate Change (IPCC) outlines that climate-related risks for natural and human systems are higher for global warming of $1.5^{\circ} \mathrm{C}$ than at present, but risks depend on the magnitude and rate of warming, levels of development and vulnerability, and on the choices of adaptation [2]. Given that the world will further urbanize during the next decade, from $56.2 \%$ in 2020 to about $60.4 \%$ by 2030 [3], these vulnerabilities are likely to intensify. Climate change can cause events such as flooding with higher frequency, intensity, and variability, affecting urban areas where density of housing is high and widespread $[4,5]$. Given that urban areas are expanding, along with 
the proportion of a population living and working within them, there is a growing need for assessing their vulnerability to disasters such as flooding. Indeed, there have been various international initiatives to address issues of uneven development and vulnerabilities within urban areas, and the New Urban Agenda (NUA) of the United Nations Human Settlement Programme (UN-Habitat) adopted in Quito, Ecuador, in October 2016 is one example of a core commitment for a transformative agenda in urban areas [4].

Implementation of the New Urban Agenda and promoting actions on urban-related Sustainable Development Goals (SDGs), such as the development of land use policies for climate resilience and adaptation to climate change, housing and slum upgrading policies, and preparation of existing institutions for disasters will require significant mobilization of financial resources to improve infrastructure and services [4]. Making cities and human settlements inclusive, safe, resilient, and sustainable (SDG11), and enhancing urban resilience in cities with rapid population growth, informal settlements, unplanned public services, and extreme income inequality requires several coordinated efforts [4,5]. The World Cities Report 2020 reaffirms that unplanned urban living leaves people vulnerable, and the COVID-19 pandemic has exposed deep inequalities which suggest that tackling the virus is more challenging in urban areas [3].

Vulnerability involves an individual or group's exposure to, capacity to cope with, and potentiality to recover from crises [5-7], and there are several international programmes and frameworks designed to assess vulnerability to disasters. One example is the Disaster Recovery Framework (DRF) of the World Bank's Global Facility for Disaster Reduction and Recovery's (GDDRR), and another is the UN Sendai Framework for Disaster Risk Reduction 2015-2030 [5]. The Sendai framework includes a set of global targets and indicators, but these operate mainly at the national level policies rather than being focused on local strategies [6,7]. Another example of a specific framework to assess vulnerability is provided by the Notre Dame Global Adaptation Index (ND-GAIN); a free open-source index that shows a country's current vulnerability to climate disruptions [8]. The aim of the index is to support the private and public sector in prioritizing climate adaptation [9]. The details of the ND-GAIN methodology are not covered here, but it assesses the vulnerability of a country by considering six life-supporting sectors: food, water, health, ecosystem services, human habitat, and infrastructure $[10,11]$. The index is based on over 74 variables, which are used to create 45 indicators spanning critical environmental, economic, and social aspects designed to measure vulnerability and readiness of 192 UN countries [11]. The inclusion of social aspects towards assessing vulnerability is included in all these frameworks and is important [12].

According to the United Nations Office for Disaster Risk Reduction (UNDRR), resilience of vulnerable communities is associated with various factors, including poverty and inequality [12]. De Almeida et al. [13] demonstrated that counties in the Amazon region face serious conditions of susceptibility to natural hazards (e.g., floods, landslides, flash floods, droughts) and this is magnified by high levels of socioeconomic inequality. In addition, the Amazon region has a very low capacity to recover and adapt to future environmental and social scenarios because of climate change [13]. All these frameworks require good quality information, and the same type of information is often required irrespective of the type of disaster (e.g., storms, floods, landslides, etc.) [8]. The need for information to enhance preparedness and plans to mitigate the impact of disasters in communities is an important dimension and examples of such initiatives include The Use of Social Work Interventions to Address Climate and Disaster Risk [12]. Traditional approaches to data collection have relied upon availability of data collected via surveys, census, tax returns, etc., but some of these can be time-consuming and expensive.

Another approach that has generated much interest is the use of Earth Observation (EO) via satellites, aircraft, and drones. However, a third approach that has been gaining some prominence in the literature is the use of tools such as Google 'Street View' (GSV) [14]. GSV images are available for several cities, as are open EO data, such as Sentinel 1- radar that supply day and night all-weather EO data [15], or Sentinel 2- optical EO data available 
every five days under cloud free conditions [16]. GSV has been used to develop different conceptual frameworks and methodologies for different purposes. Wang et al. [17] developed a new machine learning method based on GSV to assess the quality of green spaces in Guangzhou, China. They also examined exposure and access to green spaces associated with socioeconomic inequalities in urban areas, and how neighbourhoods with high socioeconomic status may have better access to quantity and quality of green spaces. Feldmeyer et al. [18] used Open Street Map (OSM) and machine learning to generate socioeconomic indicators where the availability of quality data is limited at specific temporal and spatial resolution. GSV and deep learning have been used to measure the relationships between a Green View Index (GVI) and walking behaviour [19]. Li et al. [20] assessed urban greenery using GSV for monitoring and measuring street greenery that people can see on the ground in different streets. Other examples include virtual tree surveys [21], the use of GSV to identify the elements that affect the probability that individual buildings may suffer flooding in urban areas [22], and the assessment of damage after hurricanes [14]. Hence, GSV has been used for several applications, and proves to be a useful tool for virtual field observation, especially when combined with EO. Giuliani et al. [23] used a combination of free Earth Observation (EO) and crowdsourced (e.g., OSM) EO data to model physical accessibility to urban green spaces in four European cities (Geneva, Barcelona, Goteborg, and Bristol). Unlike other studies [17-22], Giuliani et al. [23] incorporated the use of EO data but measured only one specific indicator associated with green areas.

Using GSV to populate indicators has advantages in terms of cost, but it also has limitations. For example, GSV imagery may not necessarily be up-to-date; in addition, the indicators that can be populated with the tool have to be amenable to a visual assessment (e.g., quantity and quality of infrastructure). EO can also be used in conjunction with GSV, but it too is limited to addressing indicators that can be passively 'seen' using visual wavelengths or the use of 'active' EO such as the use of radar. Image resolution can also be an important factor in EO. Hence, the assessment of urban greenspace has often been a focus with GSV- and EO-based systems in urban spaces, but there are no published examples as yet of using these tools to assess vulnerability to disasters such as flooding. The research set out in this paper addressed that gap in knowledge and sought to develop and apply an alternative method to assess vulnerability in urban area primarily using GSV along with a framework for assessing vulnerability based on the Notre Dame Global Adaptation Initiative (ND-GAIN).

The ND-GAIN approach defines adaptation as 'adjustment to the changing climate that minimize negative impacts on humans and on built and natural systems', and this involves both a mitigation of risk along with an exploration of opportunities [24]. In order to assess vulnerability to climatic hazard events such as flooding, the ND-GAIN framework uses three dimensions:

- Exposure: The size of the population and critical infrastructure (e.g., transport links, health care facilities) which may potentially be exposed to a climatic hazard event.

- Sensitivity: The extent to which a population or infrastructure may be affected by a climatic hazard event. This could be influenced by many factors such as the quality of construction of key infrastructure.

- Adaptive capacity: The ability to respond to the consequences of climate hazards, for example, the presence of emergency services or the ability to bring in support from outside the area affected.

A series of indicators may be chosen or developed to assess the three dimensions, and these can be populated in part using existing datasets such as census data [25] as well as via primary data. The logic at the heart of the ND-GAIN framework is that vulnerability to hazardous events is influenced by all three of these and is maximized when all three are weak. There are nuances, however. For example, a population may have a high level of exposure to flooding events because of geography, but the sensitivity to damage may be low, perhaps because of physical mitigations employed in construction of housing and infrastructure. Similarly, exposure and sensitivity may both be high, but there are 
good adaptations in place to ensure that affected populations are supported quickly and effectively. The latter could, for example, include early warning systems coupled with rapid evacuation systems. Hence, an appreciation of vulnerability needs to draw upon an understanding of all three of these dimensions. The ND-GAIN approach includes a fourth dimension - readiness-which in essence is the ability to enhance adaptive capacity and includes ability to attract funding as well as the ability of governance structures to make the best use of that funding. There may be various barriers at play that influence these, and one example is linked to the effectiveness of communicative tools to addressing key municipal barriers to climate adaptation [26]. One of the key findings of research based in the Netherlands is that barriers experienced by municipalities are lack of urgency, lack of knowledge of risk and measures, and actions by authorities, which are limiting their adaptation planning and implementation [26]. Enabling factors for 'readiness' can include communication and transportation infrastructure, local laws and regulations, and community-based behaviours during flooding [27].

The research reported here focuses on assessing the vulnerability of relatively rich and poor areas in the cities of Rio Branco (state of Acre) and Belem (state of Para), Brazil, to flood events. The approach is a visual interpretation and does not include machine learning or algorithms to process large numbers of images. The research followed several steps, and these are set out in the methodology section of the paper. Firstly, two cities were selected to explore resilience to flooding, and the choice of Rio Branco and Belem was based upon a series of preliminary experiences and field work visits in Brazil. Within each city, two areas that were especially prone to flooding were selected, one of them regarded as being a poorer area while another was seen as being a comparatively wealthier area. Once cities and areas were chosen and demarcated on maps, GSV was used to populate an indicator framework based upon the ND-GAIN approach set out above. The indicator values for the two cities and areas within the cities were then analysed and conclusions drawn about vulnerability to flooding, the utility of the approach taken, and its potential for further development.

\section{Material and Methods}

\subsection{Study Background—Rio Branco (Acre State) and Belem (Para State) in Brazil}

The locations in Brazil of the two cities chosen for this research (Rio Branco and Belem) are shown in Figure 1. Both cities are located within the relatively high-rainfall Amazon region.

The two cities were recommended by experts based at the National Institute of Space Research of Brazil (INPE), The Brazilian Agriculture Research Corporation (EMBRAPA), the National Centre for Disasters and Alerts and Monitoring (CEMADEN), and the Geological Service of Brazil (CPRM), which are responsible for mapping flood hazard risk areas in vulnerable areas in Brazil. All the experts consulted noted the importance and timeliness of the research, as flooding is one of the most severe natural disasters that affects livelihoods in several regions of Brazil. The specific locations within the two cities were based on suggestions provided by experts from CPRM; the cities and locations were known to have a frequency of flooding of at least two or three events in the last ten years. The Brazilian Disaster Risk Indicators (DRIB-Index) proposal by Almeida et al. [28] was also consulted to select the best locations in the Amazon region. The DRIB-Index served as a tool to help assess 32 indicators that include different levels of exposure, vulnerability, and risks in Brazil [28]. DRIB aims to capture and measure four major components: exposure to natural disasters, susceptibility of the exposed communities, coping capacities, and adaptive capacities [28]. The DRIB-Index showed a high level of vulnerability and low capacity to cope and adapt to socioenvironmental changes imposed by disasters and climate changes for several cities in the North (Amazon) and Northeast regions [2] of Brazil. Indeed, some places in the Amazon region were identified by the index as being greatly exposed to multiple hazards such as landslides, floods, flash floods, and droughts [29-31]. The Amazon region also has a very high social-vulnerability index based on indicators 
associated with employment, social dependency, race and ethnicity, availability of quality sanitation, and housing structures, amongst others [32,33]. However, the DRIB-Index does not use visual tools at the local level to evaluate specific socioeconomic features.

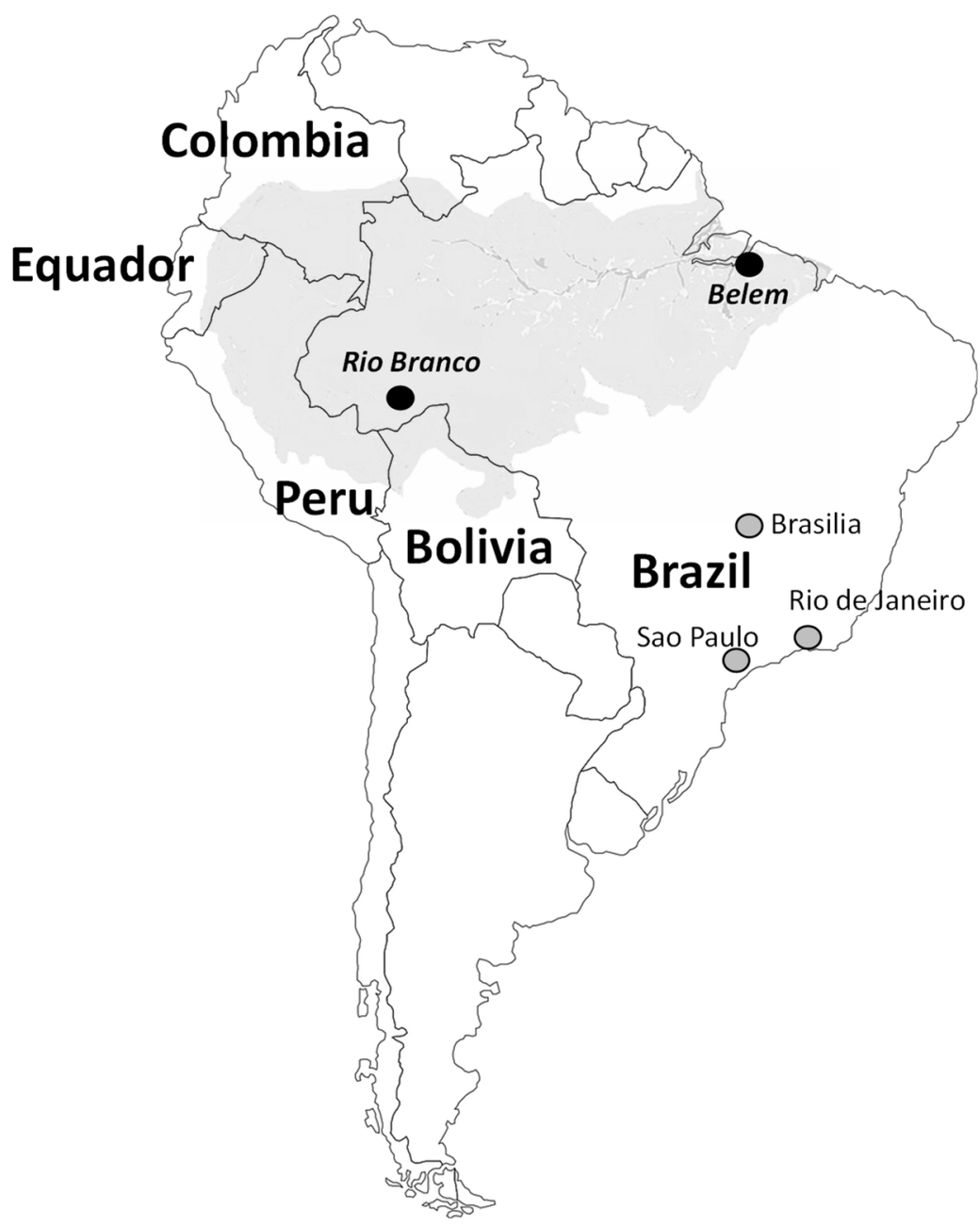

Figure 1. Study area showing two cities in the Amazon region (grey shading) in Brazil: Rio Branco (Acre State) and Belem (Para State).

The city of Rio Branco, the capital of the state of Acre in southwestern Amazon (Figure 1), is an example of an area of almost annually recurrent extreme events (e.g., floods, droughts, and forest fires) [34]. Since 1988, the city has been flooded (River Acre (the main river running through the city) levels exceeding $14.0 \mathrm{~m}$ [34]) several times, with 2015 being the most severe in recent history when the River Acre flooded for 32 consecutive days and reached $18.4 \mathrm{~m}$ in March that year. The 2015 flood affected 100,000 people, or about one-third of the city's population [34]. Rio Branco's population was estimated at 413,418 in 2020 as compared with 336,038 in the last 2010 census [35]. Rio Branco has 57\% of adequate sewage, and $20 \%$ urbanization of public roads, which shows some limitations in infrastructure in additional to population growth in the past decade [35]. Belem has an estimated population of about 149,964 in 2020 compared with 139,300 in the 2010 census [36]. In addition to the high population density, Belem has $68 \%$ of adequate sewage, and $36 \%$ urbanization of public roads [36].

The first author visited both locations for two weeks each in February and March 2020. In this period, the aim was to collect local data from local authorities (e.g., civil defence, local council, urban planning agencies, local environmental authorities). However, access to data emerged as a major challenge, despite visits to over ten local institutions in each location, including federal institutions such as EMBRAPA, federal universities, and 
the Brazilian Geological Survey (CPRM), and local institutions such as the fire brigade, civil defence, and environmental agency authorities. We assumed that talking directly to personnel in both cities would facilitate data collection. However, it was often mentioned by senior researchers in different federal institutions (e.g., CPRM, EMBRAPA, University of Para) that data availability and access to local institutions are major challenges for local researchers, and there are various reasons for this. For example, it was often mentioned by informants that federal, state, and local authorities are from different political parties and interest in climate change mitigation was at the time not part of the political agenda. Thus, access to data that shows poverty, vulnerability, exposure of minorities within flooding areas was limited or appeared not to be in the interest of local authorities to provide. This issue may have been exacerbated at the time of the fieldwork by political debates and sensitivities regarding forthcoming elections for mayoral posts. It should also be noted that, at the time of fieldwork (and also in 2021), IBGE had postponed the demographic census of 2020 due to the ongoing COVID-19 pandemic, and so the last set of available census data were from 2010 [37].

These factors and the challenging circumstances illustrate the difficulties for many researchers and authorities in accessing 'conventional', timely, and relevant data to assess local vulnerability and resilience. This reinforced the aim of this research to seek alternative, open, remote sensing approaches to assess these characteristics in the local context. Following the approach taken in the ND-GAIN framework summarized above, where vulnerability to events such as flooding is assessed via an appreciation of exposure, sensitivity and adaptation, the aspects chosen for remote sensing evaluation were designed to explore aspects such as the likelihood of floods generating material and nonmaterial losses (e.g., destruction of public and private infrastructure, reduction of accessibility to various locations, disruption of traffic flow, families losing their homes or access to dwellings) [37].

\subsection{Choice of Areas in the Two Cities}

In this study, two $1 \mathrm{~km}^{2}$ areas within each city that were known to flood regularly (Figures 2 and 3) were identified. Within each city, one area was selected as being 'poor' and one that was 'rich' on the advice of experts at CPRM based on several technical geological surveys. We used several criteria for selection (e.g., average income, house prices, number of banks, shopping malls) as indicators of poor and richer areas. However, it should be noted here that these are relative rather than absolute categorizations. Other factors such as the number of hospitals, schools, and churches were considered as indicative of the adaptive capacity to provide accommodation, psychological assistance, and shelter available locally to support dislodged people [33]. The following neighbourhoods were chosen for the research:

1. Rio Branco: Cidade Nova and Preventorio-poor area;

2. Rio Branco: City Center, Base and Seis de Agosto-richer area;

3. Belem: Terra Firme-poor area;

4. Belem: Umarizal-richer area.

The suggestions above were confirmed by advice from EMPRABA, local universities, civil defence, and other local institutions. Figure 2 gives an EO image for the poor area in Rio Branco (A), which is subject to both flooding and landslides due to unsustainable land use occupation near the river, and the richer area (B) with high levels of infrastructure (e.g., banks, government buildings, pharmacies) and also proximity to river.

The areas were demarcated using Google Earth Pro (GEP) and measured using its toolbox. The blue lines in Figures 2 and 3 are the streets available on GSV and the user can zoom in to access the street option view, or swipe up and down on the blue line. Users can move the 'yellow man' pegman and can switch between Google Earth (GE) using EO data from unique sources of Google Street View. EO imagery built into GE for every specific location provides the date, geographical coordinates, and elevation at the point of observation. In Google Earth, complete 360 degrees is available at the street level, and the user can move readily up and down the street (Figure 3). Both long and short streets 
were considered as single units of analysis. As the purpose of this study was to identify the overall vulnerability of a particular area, we used imagery available for throughout the period 2012 to 2020 .
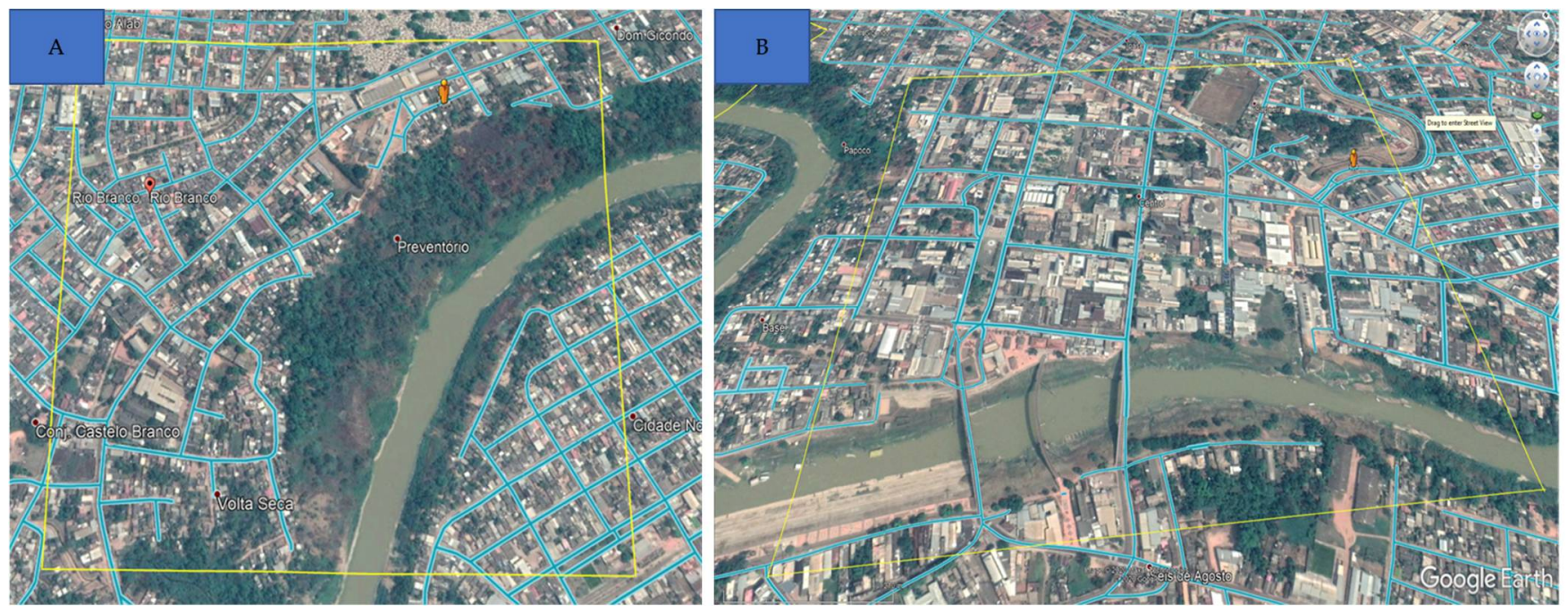

Figure 2. Google Earth EO image (27/05/2020) of selected poor (A) and richer areas (B) in Rio Branco, Acre State, 2021.
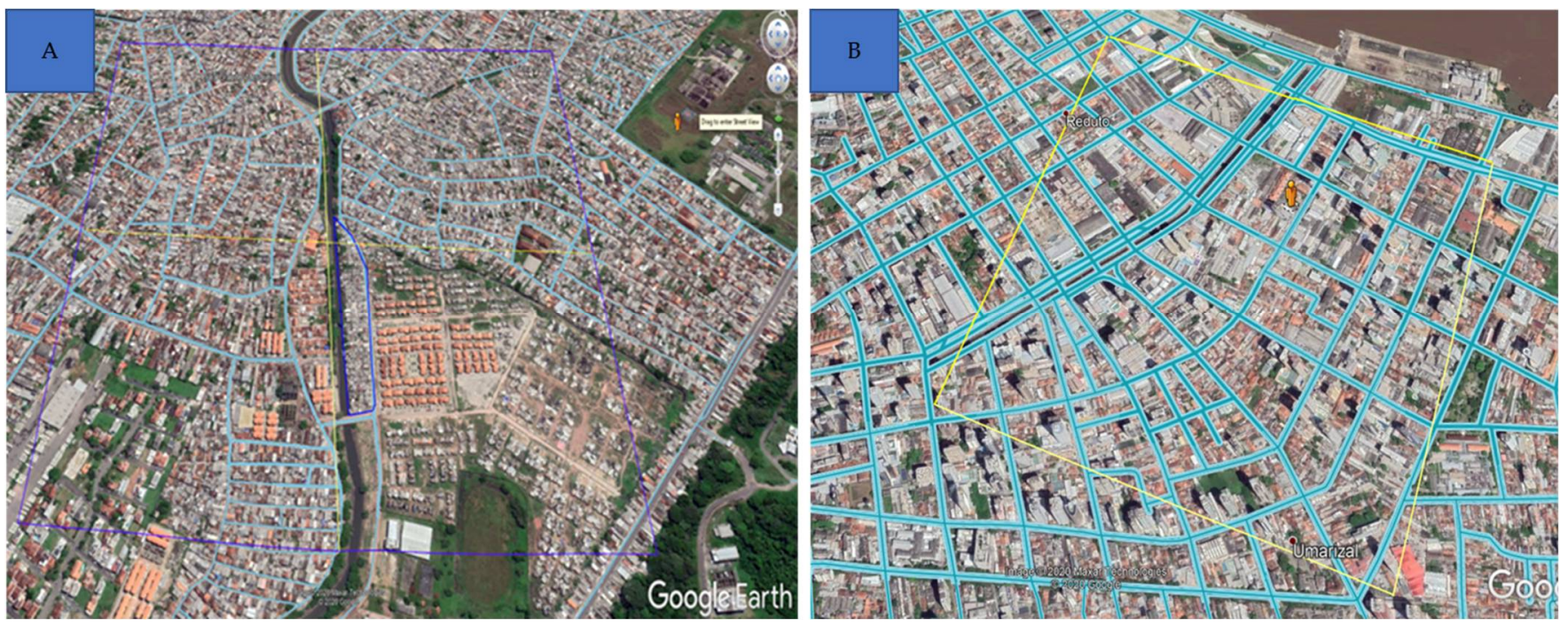

Figure 3. Google Earth EO image (27/05/2020) of selected poor (A) and richer areas (B) in Belem, Para State, 2021.

\subsection{Indicator Framework}

The indicator framework for assessing vulnerability and resilience followed the logic set out in the ND-GAIN framework outlined above [10]. Vulnerability to flooding was assumed to have three dimensions:

1. Exposure (E-factors that influence exposure to flooding);

2. Sensitivity (S- sensitivity to flooding events);

3. Adaptation (A-adaptations made to limit incidence or damage from flooding events).

The indicators and variables were then selected based on relevance to flooding and exposure of residents to floods in the selected areas. The initial identification included critical infrastructure and places to support vulnerable communities during flooding or postflooding (e.g., shelters, churches, sport facilities), or urban infrastructure that could support affected neighbourhoods during a flooding event. We considered an area at high levels 
of vulnerability if it had few assets available (e.g., weak access to hospitals, schools, poor roads, rubbish in the streets, other sensitivity indicators based on socioeconomic criteria).

We began with the list of 232 indicators of the SDGs, those of the Sendai Framework, and other indicators available in the literature. These were then selected by the authors for those associated with flooding and natural hazards. From these, those that were considered potentially amenable to visual assessment via GSV or EO were further selected. The indicators were also classified in terms of the five major capitals (or assets) of the Sustainable Livelihood Approach:

1. $\quad$ Natural (N);

2. Human $(\mathrm{H})$;

3. Social (S);

4. Financial $(\mathrm{F})$;

5. Physical (P).

Hence, indicators labelled as 'EN' come under the exposure dimension and were considered as 'natural' capitals. The result of this selection process was a framework of 45 indicators we termed the Visual Indicator Framework for Resilience (VFIOR), as set out in Table 1. The framework comprises a mix of indicators assessed by scoring and counting, and lower values (scores and counts) equate to a low resilience or capacity to adapt to flood hazards. Each of the three dimensions (Exposure, Sensitivity, and Adaptation) had differing numbers of indicators and it was not necessarily the case that all five capitals were represented within each dimension. The exposure and adaptation dimensions have indicators that span all five of the capitals, but in the sensitivity dimension the indicators only spanned the human, financial, and physical capitals.

Table 1. Indicators used to measure VIFOR framework.

\begin{tabular}{|c|c|c|c|}
\hline No. & Indicators Used to Measure Vulnerability & Type of Data Collected & Assumption \\
\hline \multicolumn{4}{|c|}{ Exposure (factors that influence exposure to flooding) } \\
\hline 1 & $\begin{array}{l}\text { * EN1: Presence and scale of waterways } \\
\text { (extent/size) }\end{array}$ & Score & $\begin{array}{l}\text { More waterways and greater extent can } \\
\text { cause greater probability of flooding }\end{array}$ \\
\hline 2 & EH1: Proximity of hospitals to waterways & Score & \multirow{6}{*}{$\begin{array}{l}\text { Proximity leads to greater probability of } \\
\text { flood damage }\end{array}$} \\
\hline 3 & EH2: Proximity of clinics to waterways & Score & \\
\hline 4 & $\begin{array}{l}\text { EH3: Proximity of pharmacies } \\
\text { to waterways }\end{array}$ & Score & \\
\hline 5 & EH4: Proximity of schools to waterways & Score & \\
\hline 6 & $\begin{array}{l}\text { EH5: Proximity of houses near } \\
\text { to waterways }\end{array}$ & Score & \\
\hline 7 & EH6: Proximity of business to waterways & Score & \\
\hline 8 & $\begin{array}{l}\text { EH7: Proportion of business near to } \\
\text { ground level }\end{array}$ & Score & $\begin{array}{c}\text { Being near ground level equals a higher } \\
\text { chance of flood damage. Some level of } \\
\text { elevation above ground. }\end{array}$ \\
\hline 9 & $\begin{array}{l}\text { ES1: Proximity of places of worship } \\
\text { to waterways }\end{array}$ & Score & \multirow[t]{2}{*}{$\begin{array}{l}\text { Proximity leads to greater probability of } \\
\text { flood damage }\end{array}$} \\
\hline 10 & EF1: Proximity of banks to waterways & Score & \\
\hline 11 & $\begin{array}{l}\text { EP1: Proportion of business at direct } \\
\text { street level }\end{array}$ & Score & \multirow{2}{*}{$\begin{array}{l}\text { Being at ground level means a higher } \\
\text { chance of flood damage. Direct at the street } \\
\text { or pavement without elevation. }\end{array}$} \\
\hline 12 & $\begin{array}{c}\text { EP2: Proportion of housing at direct } \\
\text { street level }\end{array}$ & Score & \\
\hline
\end{tabular}


Table 1. Cont.

\begin{tabular}{cccc}
\hline No. & Indicators Used to Measure Vulnerability & Type of Data Collected & Assumption \\
\hline $\mathbf{1 3}$ & * EP3: Quality of road surface & Score & $\begin{array}{c}\text { Indicator of flood damage but also is } \\
\text { important in terms of access for emergency } \\
\text { vehicles and people wishing to leave }\end{array}$ \\
\hline $\mathbf{1 4}$ & EP4 General state of repair of buildings & Score & Indicator of flood damage but also poverty \\
\hline $\mathbf{1 5}$ & EP5: Presence of soil erosion & Score & Indicator of flood damage \\
\hline $\mathbf{1 6}$ & EP6: Rubbish in the streets & Score & $\begin{array}{c}\text { Indicator of poverty, but also more rubbish } \\
\text { leads to a greater chance of drainage } \\
\text { systems being blocked }\end{array}$ \\
\hline
\end{tabular}

\section{Sensitivity (sensitivity to flooding events)}

\begin{tabular}{|c|c|c|c|}
\hline 17 & $\begin{array}{l}\text { SH1: Density of housing/construction in } \\
\text { the flooding areas }\end{array}$ & Score & $\begin{array}{l}\text { Number of houses per street. Density and } \\
\text { intersection with mix land uses. }\end{array}$ \\
\hline 18 & SH2: Sturdiness of dwellings & Score & $\begin{array}{l}\text { Quality of materials of houses } \\
\text { and buildings. }\end{array}$ \\
\hline 19 & SF1: Cleanliness of streets & Score & Rubbish in the streets \\
\hline 20 & SF2: Presence of graffiti & Score & Number of graffiti in public spaces \\
\hline 21 & SF3: Unoccupied/boarded-up buildings & Score & Empty buildings or facilities without use \\
\hline 22 & SF4: Incidence of decaying buildings & Score & Buildings without use \\
\hline 23 & SF5: Value of cars parked on streets & Score & $\begin{array}{l}\text { New and expensive cars to damaged and } \\
\text { old cars. }\end{array}$ \\
\hline 24 & * SP1: Type of road surface & Score & $\begin{array}{l}\text { High quality asphalt to various low-quality } \\
\text { pavement layers. }\end{array}$ \\
\hline 25 & *SP2: Overall road width & Score & $\begin{array}{l}\text { Size of road width and road markings used, } \\
\text { including those across the carriageway. }\end{array}$ \\
\hline 26 & $\begin{array}{l}\text { SP3: Quality of pavements/sidewalks } \\
\text { to roadsides }\end{array}$ & Score & $\begin{array}{c}\text { Allows cars and people to move during } \\
\text { flooding events. Quality of sidewalks, } \\
\text { which allows effective mobility } \\
\text { of pedestrians. }\end{array}$ \\
\hline 27 & SP4: Presence of water on the streets & Score & Poor drainage that can lead to flooding. \\
\hline \multicolumn{4}{|c|}{ Adaptation (to flooding) } \\
\hline 28 & $\begin{array}{c}* \text { AN1: Proportion of green areas } \\
\text { and vegetation }\end{array}$ & Proportion $(\%)$ & Green spaces help with drainage \\
\hline 29 & $\begin{array}{l}\text { AH1: Number of hospitals (public } \\
\text { and private) }\end{array}$ & Count & \multirow{3}{*}{$\begin{array}{l}\text { Assets to support health care during a } \\
\text { flood event }\end{array}$} \\
\hline 30 & AH2: Number of clinics & Count & \\
\hline 31 & AH3: Number of pharmacies & Count & \\
\hline 32 & AH4: Number of schools & Count & $\begin{array}{l}\text { School premises can provide spaces for } \\
\text { people to gather in the event of a flood and } \\
\text { be supported. }\end{array}$ \\
\hline 33 & $\begin{array}{l}\text { AH5: Number of community public } \\
\text { health centre }\end{array}$ & Count & Supports health care in the event of a flood \\
\hline 34 & $\begin{array}{l}\text { AH6: Number of universities (public } \\
\text { and private) }\end{array}$ & Count & \multirow{3}{*}{$\begin{array}{l}\text { Physical premises can provide spaces for } \\
\text { people to gather in the event of a flood and } \\
\text { be supported }\end{array}$} \\
\hline 35 & AS1: Number places of worship & Count & \\
\hline 36 & AS2: Number of sport halls & Count & \\
\hline 37 & AS3: Number of police stations & Count & \multirow{2}{*}{$\begin{array}{l}\text { Provide support/security during a } \\
\text { flood event }\end{array}$} \\
\hline 38 & AS4: Number of fire stations & Count & \\
\hline
\end{tabular}


Table 1. Cont.

\begin{tabular}{|c|c|c|c|}
\hline No. & Indicators Used to Measure Vulnerability & Type of Data Collected & Assumption \\
\hline 39 & $\begin{array}{l}\text { AF1: Number of banks (access to local } \\
\text { financial support) }\end{array}$ & Count & Access to cash and financial services \\
\hline 40 & AF2: Number of cooperative associations & Count & $\begin{array}{l}\text { Supports with information, shelter and } \\
\text { community-based cooperation to support } \\
\text { socioeconomic recovery }\end{array}$ \\
\hline 41 & $\begin{array}{l}\text { * AP1: Presence of flood defences } \\
\text { (strengthened banks etc.) }\end{array}$ & Count & $\begin{array}{l}\text { Provide defence for rivers do not burst } \\
\text { their banks }\end{array}$ \\
\hline 42 & AP2: Quality of flood defences & Score & $\begin{array}{l}\text { Natural and artificial strengthened banks } \\
\text { to prevent flooding }\end{array}$ \\
\hline 43 & AP3: Quality of street drainage systems? & Score & $\begin{array}{l}\text { Surface water drainage systems to } \\
\text { prevent flooding }\end{array}$ \\
\hline 44 & $\begin{array}{l}\text { * AP4: Number or bridges (bridges } \\
\text { for vehicles) }\end{array}$ & Count & $\begin{array}{c}\text { Provide access and mobility in } \\
\text { flooding areas }\end{array}$ \\
\hline 45 & AP5: Durability of bridges (to flooding) & Score & $\begin{array}{l}\text { Type of material from small scale wood } \\
\text { bridges to large scale concrete bridges. } \\
\text { Resilience of infrastructure to avoid bridge } \\
\text { collapse during flooding. }\end{array}$ \\
\hline
\end{tabular}

Note: Indicators marked with an asterisk $\left(^{*}\right)$ are potentially measurable via Earth Observation.

In the Exposure dimension (16 indicators) many of the indicators refer to distance of the community assets (hospitals, clinics, schools, etc.) from a source of flooding. The assumption here is that the farther away an asset is from the source of flooding, then the lower the likelihood is that it would be exposed to damage as a result of flooding. Further included here are indicators that assess whether an asset is at street level or raised (e.g., on the second floor or higher of a multitier building). The Sensitivity dimension has a total of 11 indicators, most of which address the exposure of assets to damage once flooding occurs. The assumptions here are that buildings, roads, and sidewalks that are of poor quality suggest that they may be or have been readily damaged by flood events and/or that they may also be sensitive to further degradation. To some extent these are also indicators of wealth and lack of investment. One of the indicators specifically assessed whether there is standing water on the street, which would suggest a lack of drainage (this depends on when the GSV images were taken). For the Adaptation dimension (18 indicators, the largest number of indicators of the three dimensions), the indicators are mostly counts of important assets such as the number of hospitals (public and private), schools, pharmacies, universities (public and private), clinics, places of worship, sports halls, number of police stations, and number of banks. These are important in terms of health care provision during and after a flooding event, but also of the ability to improve human capital (education), social capital (cooperatives), and financial capital (banks). Further included here are counts of assets such as emergency service stations (police, fire stations) and flood defences (e.g., barriers) and drainage systems. Assessing adaptation in terms of physical entities that can be observed via GSV or EO is admittedly a narrower perspective than envisaged in the NDGAIN framework. In ND-GAIN, adaptation (or more precisely, adaptive capacity) is seen as an ability to manage flood events and includes the presence of early warning systems and management plans. However, in the VIFOR framework, adaptation was limited to an assessment of structures such as number of facilities (e.g., AS1 to AS2), or specific flood defence systems such as the quality of flood defences (AP2) or the quality of street drainage systems (AP3). There is a relationship here in the sense that the presence of structures such as medical facilities and police and fire stations are important for helping deliver any plans that authorities may have in place, although counting such facilities says nothing about their quality in terms of number of staff available, their training and preparedness, and availability of required equipment. Therefore, a thorough assessment of adaptation 
would need to go beyond what can be seen and this would necessitate interviews with stakeholders at all levels, including the local community, although there can be constraints here as noted above and especially during a pandemic.

All three dimensions of VIFOR overlap to some extent and there are indicators that could be moved to a different category. For example, under Sensitivity, the indicators that capture building quality (SH2, SF3, and SF4) could also be classified under Adaptation; one of the responses that people could make to improve resilience would be to strengthen their dwellings. Similarly, the quality of the road surface (EP3) in the Exposure dimension could be placed under Sensitivity. It is included under Exposure as it is assumed that a poorquality road indicates greater damage resulting from flooding, but that can also be applied to the type of road surface (SP1), as paved roads could decay as the result of successive flood events. For this reason, it was decided to weigh all the indicators equally and not apply weights to the three dimensions. Thus, in a sense it does not really matter where an indicator appears in the framework, it is still weighted equally, and the classification is only for ease of use.

It should be noted that some indicators in the VIFOR framework have the potential for assessment via EO. These are demarcated in Table 1 with an asterisk. The presence of waterways (EN1), the proportion of green areas (AN1), flood defences (AP1), and bridges (AP4) are obvious examples, as indeed are indicators of road width (SP2) and road quality (EP3) and material of construction (SP1). There are other indicators that may not be so obviously assessable via EO, such as the number of banks (AF1) and cooperative associations (AF2). These institutions often occupy spaces within larger buildings and provide no visual clues readily tractable by $\mathrm{EO}$ to their use.

\subsection{Data Collection and Analysis}

The indicators in Table 1 were populated via a combination of counts and scoring. For all the indicators, all the streets in the $1 \mathrm{~km}^{2}$ quadrant (lines in Figures 2 and 3) were 'walked' virtually in GSV. We focused on $1 \mathrm{~km}^{2}$ due to logistical issues and time constraints to cover all the streets within the boundaries of the two cities. Hence, we selected two areas (rich and poor) for each city based on the recommendations of experts along with the criteria noted above. The number of streets 'walked' in each of the areas is shown in Table 2. Care was taken to ensure that a single asset existing on a junction between streets was not recorded more than once. However, while the streets differed in terms of length, this was not accounted for in the assessment and long streets were treated the same as short streets. Hence, each indicator was not weighted for variation in the length of the street. For those indicators assessed via scores (mainly Exposure and Sensitivity), the scores ranged from 1 to 5 , with the polarity set to 1 representing low resilience and 5 representing high resilience (to flood events) and the midpoint score of 3 representing a moderate level of resilience 'performance' for the indicator. For count-type scores (mainly in the Adaptation dimension) these are 'raw' data and no midpoint assessment of a level of resilience is given except for the fact that a higher number is indicative of greater resilience and average values of zero or small fractious per street suggest low resilience.

Table 2. Number of streets assessed for the indicators in Table 1.

\begin{tabular}{|c|c|c|}
\hline City & Area & Number of Streets \\
\hline \multirow[t]{2}{*}{ Rio Branco } & Poor & 42 \\
\hline & Rich & 29 \\
\hline \multirow[t]{2}{*}{ Belem } & Poor & 45 \\
\hline & Rich & 20 \\
\hline
\end{tabular}

The construction patterns of dwellings are often not designed to withstand flooding, especially in regions with significant inequalities [38]. In Figure 4, we used GSV to classify houses and structures in terms of their likelihood of flooding as described in the following 
categories: very high, high, high, medium, low, and very low. We assumed that very high (score 5) is the most adaptable structure in the sense of the building and its contents being best able to avoid flood damage (often located in richer areas), and very low (score 1) is the least adaptable structure to cope with a flooding event (i.e., building and contents damage is most likely). In the low and very low scores, we identify houses principally situated at street level, limited paved roads, and high concentration of houses. In high and very high categories, houses are located in buildings situated above street level that are less exposed to floods. EP2 refers to the proportion of housing at street level, or likely to flood during an event. A similar scoring system was used to describe the general state of repair of buildings (Figure 5) in the following categories: very low, low, medium, high, and very high. This refers to the quality of the houses, type of materials, and construction. For example, in Figure 5, scores 4 and 5 represent good quality construction indicating resilient infrastructure when compared with scores 1 and 2. A further example of the scoring system is that for SP3 (Figure 6), which refers to the quality of pavements and sidewalks.

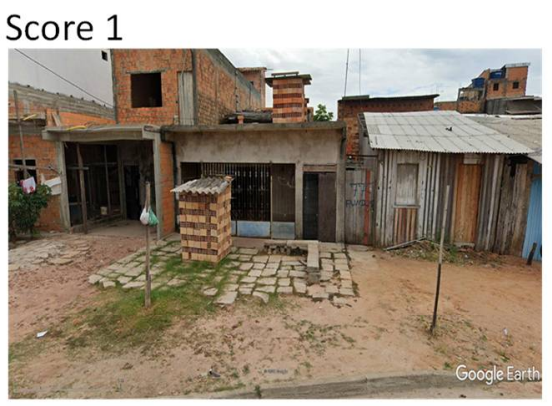

\section{Score 2}

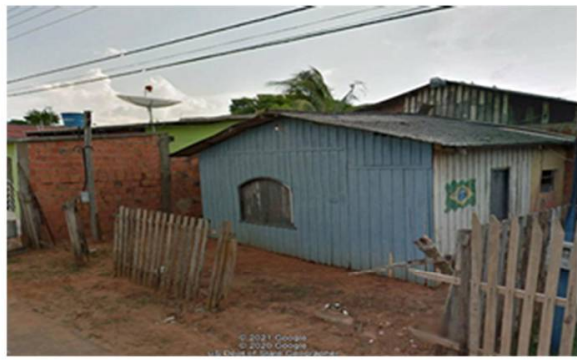

Score 5
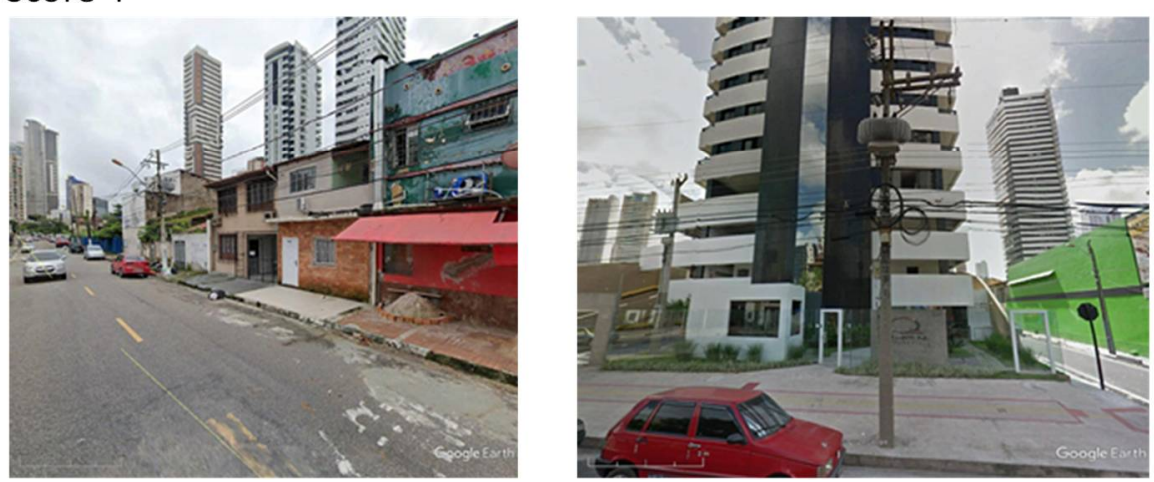

Score 3

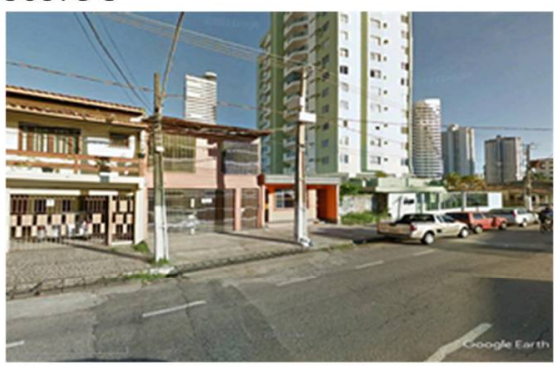

Figure 4. Example of the scoring system showing proportion of houses and structures likely to flood. GSV images from Rio Branco and Belem. EP2: Proportion of housing at direct street level (likely to flood), Score 1 = Very high (80-100\%), Score $2=$ High $(60-80 \%)$, Score $3=$ Medium $(40-60 \%)$, Score $4=$ Low $(20-40 \%)$, Score 5 = Very low $(0-20 \%)$. 
Score $1=$ Very low

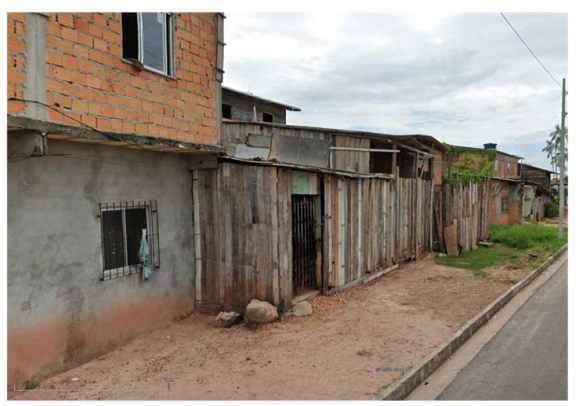

Score $4=$ High

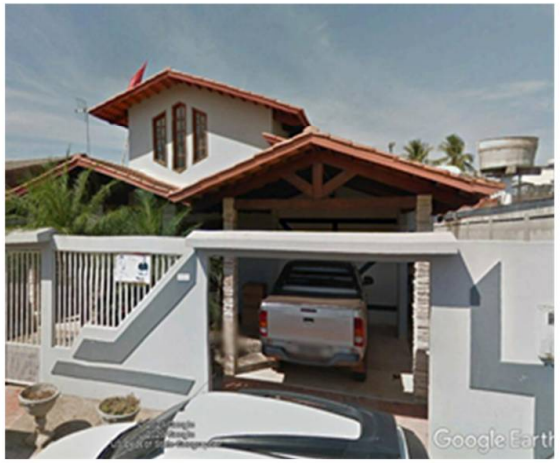

Score 2 = Low

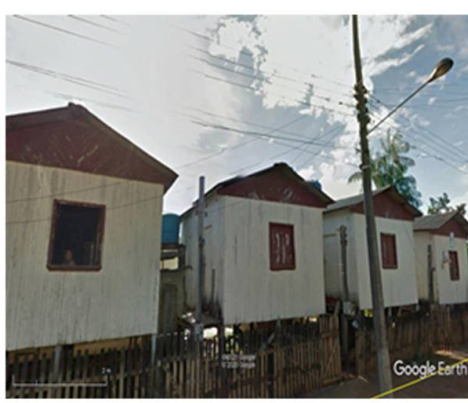

Score $5=$ Very high

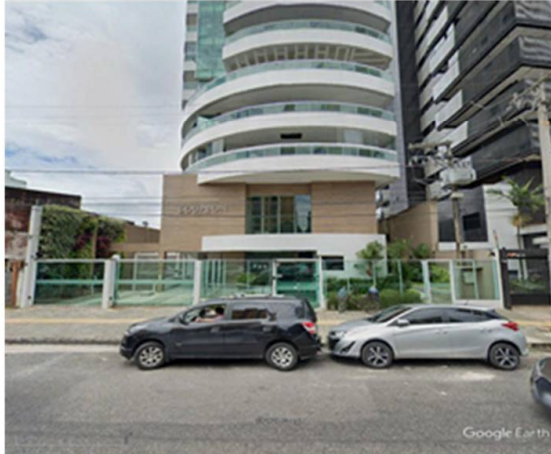

Figure 5. Examples of the scoring system showing the general state of repair from buildings. GSV images from Rio Branco and Belem. EP4: General state of repair of buildings, Score 1 = Very low, Score 2 = Low, Score 3 = Medium, Score 4 = High, Score $5=$ Very high .

Score 1

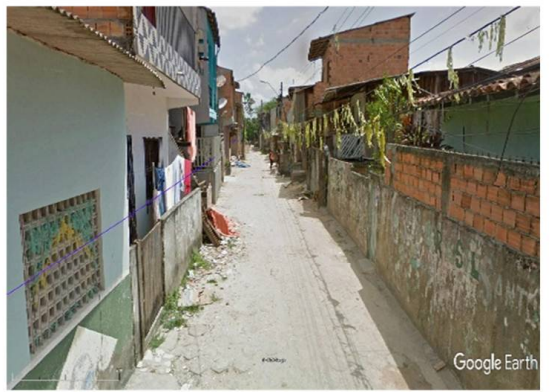

Score 2

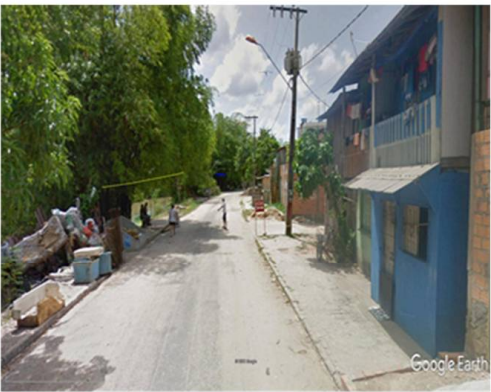

Score 3= Medium

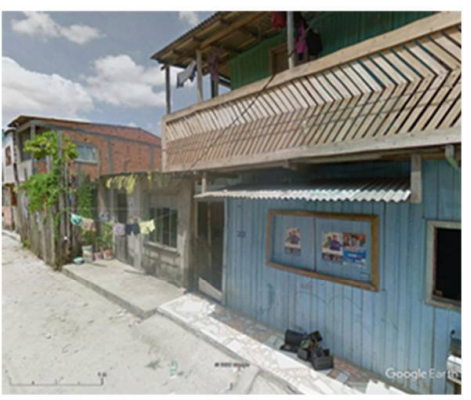

\section{Score 4}

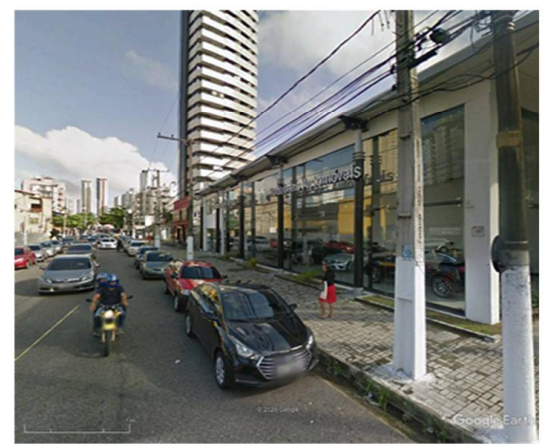

\section{Score 5}

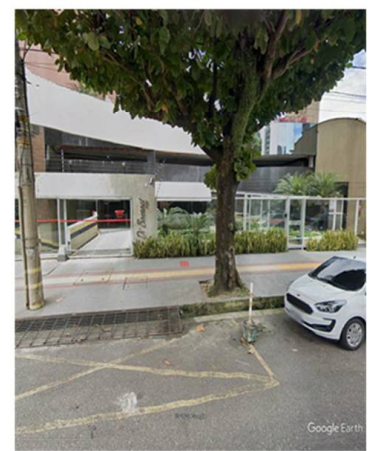

Score 3

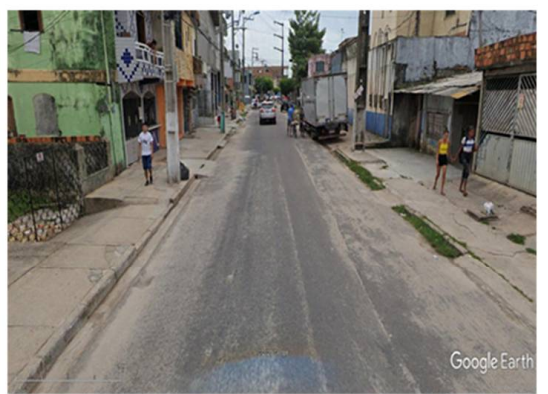

Figure 6. Examples of the scoring system showing quality of pavements/sidewalks. GSV images from Rio Branco and Belem. SP3: Score 1 = Very poor, Score 2 = Poor, Score $3=$ Medium, Score $4=$ High, Score 5 = Very high . 


\section{Results}

The means and standard deviations (SD) for the indicators as assessed using GSV observation data for the selected streets/city areas are shown in Table 3. Further shown are the number of streets $(\mathrm{N})$ for which the indicator could be assessed. The latter is important; for example, the indicators which assess proximity to a source of flooding were not relevant in some cases where the unit (hospital, clinic, etc.) did not exist within the $1 \mathrm{~km}^{2}$ grid. There is insufficient space here to describe all the indicators in Table 3, so only a few examples are highlighted. For the two poor areas there are issues with houses and businesses more likely to be located near ground level. The presence and scale of waterways in the poor area of Belem (EN1 average score: 4.11) is higher compared with that of Rio Branco (EN1 average score: 3.61). Indeed, in Belem, many of the businesses and houses are located near canals that are often related to poor technical maintenance of river channels, and disposal of rubbish in the canals also contributes to flooding. In Rio Branco, some houses in poor areas located near the Acre River are built with two floors, while in many of the poorer areas in Belem located near the canals, houses have only one floor. The poor area in Belem has a worse drainage system (AP3 average score 1.62) when compared with the poor area of Rio Branco (AP3 average score: 2.6), which relates to the quality of drainage as an indicator for Adaptation during flooding events. The density of housing is higher in the Belem poor area (SH1 average score: 2) when compared with the Rio Branco poor area (SH1 average score: 2.86). The streets in the poorer area of Rio Branco are cleaner (SF1 average score: 2.76) when compared to Belem (SF1 average score: 2.38), and there is more graffiti in the poorer area of Belem (SF2 average score: 3.27) when compared to Rio Branco (SF2 average score: 3.88). The quality of pavements and sidewalks in Belem (SP3 average score: 1.58) was also lower than found in the poor area of Rio Branco (SP3 average score: 2.33).

Table 3. VIFOR framework scores for the 45 indicators based on GSV observation of streets in the selected areas of Rio Branco and Belem.

\begin{tabular}{|c|c|c|c|c|c|c|c|c|c|c|c|c|}
\hline \multirow[b]{3}{*}{ Indicator } & \multicolumn{6}{|c|}{ Rio Branco } & \multicolumn{6}{|c|}{ Belem } \\
\hline & \multicolumn{3}{|c|}{ Poor Area } & \multicolumn{3}{|c|}{ Rich Area } & \multicolumn{3}{|c|}{ Poor Area } & \multicolumn{3}{|c|}{ Rich Area } \\
\hline & $\mathbf{N}$ & Mean & SD & $\mathbf{N}$ & Mean & SD & $\mathbf{N}$ & Mean & SD & $\mathbf{N}$ & Mean & SD \\
\hline \multicolumn{13}{|c|}{ (a) Exposure dimension } \\
\hline EN1 & 42 & 3.62 & 0.85 & 29 & 3.41 & 0.98 & 45 & 4.11 & 0.91 & 20 & 4.25 & 1.33 \\
\hline EH1 & 0 & - & - & 0 & - & - & 0 & - & - & 6 & 2.17 & 1.33 \\
\hline $\mathrm{EH} 2$ & 1 & 2 & - & 11 & 2.45 & 0.82 & 3 & 1 & 0 & 10 & 2.4 & 0.84 \\
\hline EH3 & 1 & 3 & - & 12 & 2.08 & 0.67 & 0 & - & - & 7 & 1.14 & 0.69 \\
\hline EH4 & 3 & 3 & 1 & 10 & 2 & 0.47 & 3 & 1.33 & 0.58 & 6 & 2.83 & 0.75 \\
\hline EH5 & 41 & 2.54 & 1.12 & 29 & 2.59 & 1.12 & 43 & 1.33 & 0.57 & 19 & 2.21 & 0.85 \\
\hline EH6 & 39 & 2.69 & 1.06 & 29 & 2.41 & 1.21 & 42 & 1.31 & 0.6 & 17 & 2.12 & 0.93 \\
\hline EH7 & 39 & 2.15 & 0.74 & 29 & 2.34 & 1.04 & 43 & 1.12 & 0.45 & 18 & 2.33 & 0.77 \\
\hline ES1 & 13 & 2 & 1 & 9 & 1.67 & 1.32 & 28 & 1.25 & 0.52 & 3 & 1.67 & 1.15 \\
\hline EF1 & 2 & 3 & 0 & 14 & 2 & 0.96 & 0 & - & - & 5 & 1.4 & 0.89 \\
\hline EP1 & 40 & 2.25 & 0.78 & 29 & 2.1 & 0.86 & 44 & 1.2 & 0.46 & 18 & 2.44 & 0.92 \\
\hline EP2 & 42 & 2.26 & 0.8 & 29 & 2.17 & 0.76 & 45 & 1.36 & 0.53 & 19 & 3.11 & 1.52 \\
\hline EP3 & 42 & 2.74 & 0.8 & 29 & 3.45 & 0.69 & 45 & 1.96 & 0.67 & 20 & 3.85 & 0.93 \\
\hline EP4 & 42 & 2.71 & 0.46 & 29 & 3.55 & 0.83 & 45 & 2 & 0.64 & 20 & 3.85 & 1.04 \\
\hline EP5 & 42 & 3.1 & 0.98 & 29 & 4 & 0.8 & 45 & 4.07 & 0.89 & 20 & 5 & 0 \\
\hline EP6 & 42 & 3.05 & 0.62 & 29 & 3.45 & 1.21 & 45 & 2.96 & 0.77 & 20 & 3.9 & 0.64 \\
\hline \multicolumn{13}{|c|}{ (b) Sensitivity dimension } \\
\hline SH1 & 42 & 2.86 & 0.65 & 29 & 3.31 & 0.66 & 45 & 2 & 0.48 & 20 & 3.45 & 1 \\
\hline $\mathrm{SH} 2$ & 42 & 2.71 & 0.64 & 29 & 3.38 & 0.56 & 45 & 2.22 & 0.56 & 20 & 3.55 & 1.19 \\
\hline SF1 & 42 & 2.76 & 0.53 & 29 & 3.24 & 0.87 & 45 & 2.38 & 0.53 & 20 & 3.4 & 1.23 \\
\hline SF2 & 42 & 3.88 & 0.67 & 29 & 4.1 & 1.01 & 45 & 3.27 & 0.86 & 20 & 3.7 & 1.26 \\
\hline SF3 & 42 & 3.6 & 0.63 & 29 & 4.14 & 0.99 & 45 & 3.33 & 0.77 & 20 & 4.1 & 1.07 \\
\hline SF4 & 42 & 3.4 & 0.8 & 29 & 3.86 & 1.13 & 45 & 2.38 & 0.68 & 20 & 4.2 & 0.83 \\
\hline SF5 & 42 & 2.76 & 0.53 & 29 & 3.24 & 0.64 & 45 & 2.24 & 0.68 & 20 & 3.6 & 0.82 \\
\hline
\end{tabular}


Table 3. Cont.

\begin{tabular}{|c|c|c|c|c|c|c|c|c|c|c|c|c|}
\hline \multirow[b]{3}{*}{ Indicator } & \multicolumn{6}{|c|}{ Rio Branco } & \multicolumn{6}{|c|}{ Belem } \\
\hline & \multicolumn{3}{|c|}{ Poor Area } & \multicolumn{3}{|c|}{ Rich Area } & \multicolumn{3}{|c|}{ Poor Area } & \multicolumn{3}{|c|}{ Rich Area } \\
\hline & $\mathbf{N}$ & Mean & SD & $\mathbf{N}$ & Mean & SD & $\mathbf{N}$ & Mean & SD & $\mathbf{N}$ & Mean & SD \\
\hline SP1 & 42 & 2.79 & 0.72 & 29 & 3.31 & 0.89 & 45 & 2.11 & 0.49 & 20 & 3.7 & 1.03 \\
\hline SP2 & 42 & 2.6 & 0.63 & 29 & 3.38 & 0.86 & 45 & 1.47 & 0.55 & 20 & 3.4 & 1.14 \\
\hline SP3 & 42 & 2.33 & 0.82 & 29 & 3.34 & 1.14 & 45 & 1.58 & 0.75 & 20 & 3.6 & 1.27 \\
\hline SP4 & 42 & 3.81 & 0.8 & 29 & 4 & 0.85 & 45 & 3.67 & 1 & 20 & 4.25 & 0.97 \\
\hline \multicolumn{13}{|c|}{ (c) Adaptation dimension } \\
\hline AN1 & 42 & 2.1 & 0.66 & 29 & 2.28 & 1.03 & 45 & 1.11 & 0.49 & 20 & 2.1 & 0.97 \\
\hline AH1 & 42 & 0 & 0 & 29 & 0 & 0 & 45 & 0 & 0 & 20 & 0.4 & 0.75 \\
\hline $\mathrm{AH} 2$ & 42 & 0.02 & 0.15 & 29 & 0.41 & 0.73 & 45 & 0.04 & 0.21 & 20 & 0.65 & 0.81 \\
\hline $\mathrm{AH} 3$ & 42 & 0.1 & 0.48 & 29 & 0.41 & 0.82 & 45 & 0 & 0 & 20 & 0.9 & 2.1 \\
\hline $\mathrm{AH} 4$ & 42 & 0.07 & 0.26 & 29 & 0.48 & 0.74 & 45 & 0.07 & 0.25 & 20 & 0.5 & 0.89 \\
\hline AH5 & 42 & 0.07 & 0.26 & 29 & 0.07 & 0.26 & 45 & 0 & 0 & 19 & 0.05 & 0.23 \\
\hline AH6 & 42 & 0 & 0 & 29 & 0.03 & 0.19 & 45 & 0 & 0 & 20 & 0.2 & 0.41 \\
\hline AS1 & 42 & 0.43 & 0.74 & 29 & 0.28 & 0.45 & 45 & 1.02 & 1.23 & 19 & 0.21 & 0.42 \\
\hline AS2 & 42 & 0.02 & 0.15 & 29 & 0.24 & 0.58 & 45 & 0.04 & 0.21 & 20 & 0.3 & 0.57 \\
\hline AS3 & 42 & 0 & 0 & 29 & 0.14 & 0.35 & 45 & 0 & 0 & 20 & 0.05 & 0.22 \\
\hline AS4 & 42 & 0 & 0 & 29 & 0 & 0 & 45 & 0 & 0 & 20 & 0 & 0 \\
\hline AF1 & 42 & 0.05 & 0.22 & 28 & 0.79 & 1.42 & 45 & 0 & 0 & 20 & 0.4 & 0.94 \\
\hline AF2 & 42 & 0.02 & 0.15 & 28 & 0.36 & 0.56 & 45 & 0 & 0 & 20 & 0 & 0 \\
\hline AP1 & 38 & 0.03 & 0.16 & 29 & 0.21 & 0.41 & 32 & 0.03 & 0.18 & 13 & 0.38 & 0.51 \\
\hline AP2 & 4 & 0.75 & 1.5 & 6 & 3.33 & 0.82 & 10 & 0.9 & 0.57 & 9 & 4 & 0.87 \\
\hline AP3 & 42 & 2.6 & 0.77 & 29 & 3.07 & 0.8 & 45 & 1.62 & 0.65 & 20 & 3.4 & 1.05 \\
\hline AP4 & 21 & 0.05 & 0.22 & 29 & 0.07 & 0.26 & 33 & 0.33 & 0.74 & 11 & 0.55 & 0.52 \\
\hline AP5 & 3 & 1 & 1.73 & 2 & 5 & 0 & 8 & 1.25 & 1.16 & 6 & 4 & 0 \\
\hline
\end{tabular}

Note: Means and standard deviation (SD) are based on the streets that were assessed for the indicators. $\mathrm{N}$ is the number of streets where the indicator could be assessed.

For the two richer areas, the one in Belem is less exposed to waterways (EN1 average score: 4.25) when compared to the richer area in Rio Branco (EN1 average score: 3.41). The general state of repair of buildings, which includes the quality of the materials and condition of buildings, is similar for the richer areas of Belem (EP4 average score: 3.85 ) and Rio Branco (EP4 average score: 3.55). Richer areas in Belem include large numbers of high-rise buildings, which may only flood at street level (access points to buildings), but flooding is unlikely to cause damage more widely to the building. The proximity of businesses to waterways in the richer area of Belem (EH6 average score: 2.12) is similar to that for Rio Branco (EH6 average score: 2.41) and suggests that businesses in both areas are relatively close to local waterways. The quality of pavements/sidewalks to roadsides in the richer areas of Belem (SP3 average score: 3.6) and Rio Branco (SP3 average score: 3.34), and the quality of street drainage in the rich of Belem (AP3 average score: 3.4) and in Rio Branco (AP3 average score 3.07), suggest a medium level of vulnerability and the indicators certainly suggest better levels of resilience compared to the poorer areas of the two cities.

The distribution of scores for the Exposure and Sensitivity dimensions to resilience, the two that were assessed entirely via scoring, are shown in Figure 7 . The results suggest that the distribution of scores was towards the higher end of the five-point scale for the richer areas (Figure $7 \mathrm{~b}, \mathrm{~d}$ ) compared with the poorer ones (Figure $7 \mathrm{a}, \mathrm{c}$ ). Indeed, the poorer area of Belem (Figure 7c) had scores that were especially on the low side. Hence, for the Exposure and Sensitivity dimensions, there is a sense here that poorer areas have a lower resilience compared with richer areas. To allow for a direct comparison of resilience across all three dimensions (Exposure, Sensitivity, and Adaptation), the mean score or count per street was calculated for the 45 indicators and the results are presented in Figure 8 as radar (or amoeba) diagrams. Higher values for any of the indicators suggest a greater resilience. The overall pictures of resilience presented in Figure 8 suggest that there is a clear division between Exposure and Sensitivity between poor and richer areas. However, the poor area 
Rio Branco (Figure 8a) would appear to have a higher level of Exposure when compared with the poor area in Belem (Figure 8c). Interestingly, the Adaptation dimension is quite low for all four areas but is especially low for the two poor areas.
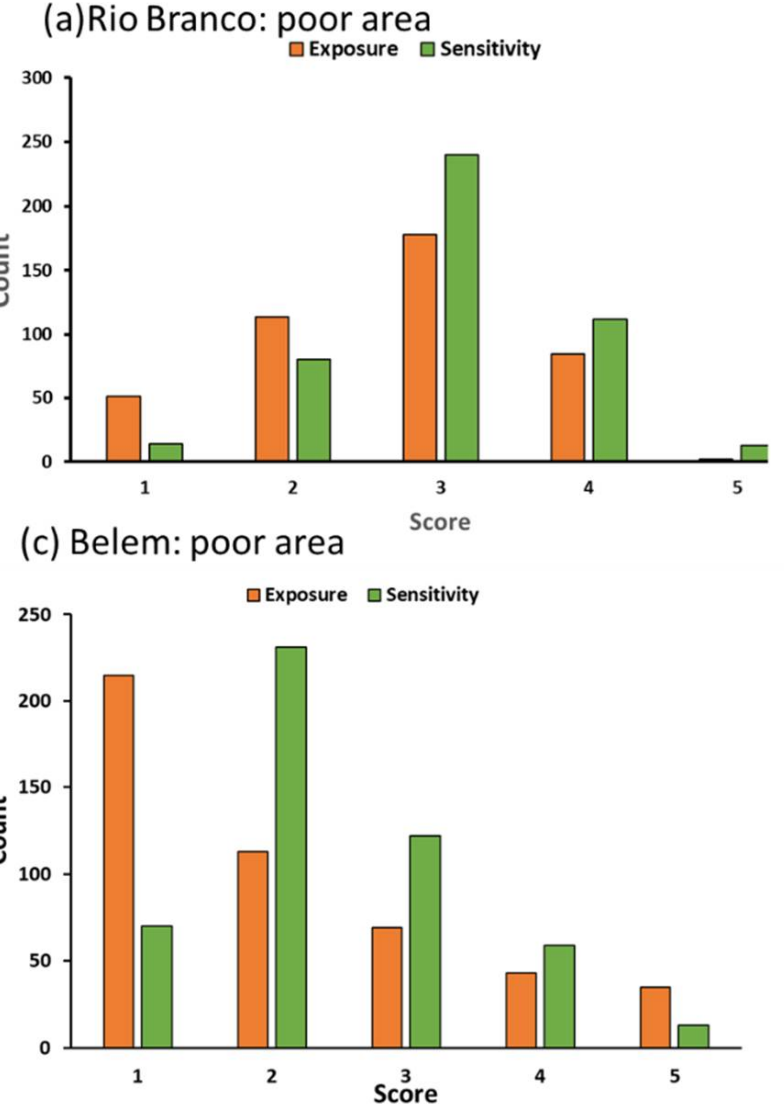

(b) Rio Branco: rich area

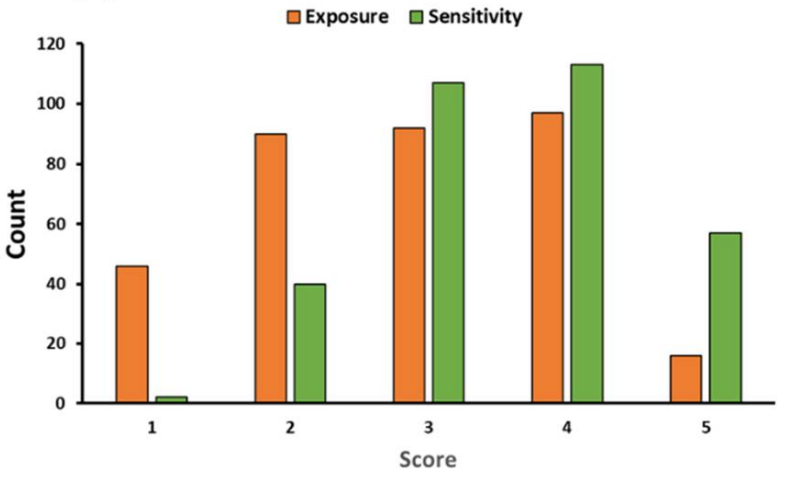

(d) Belem: rich area

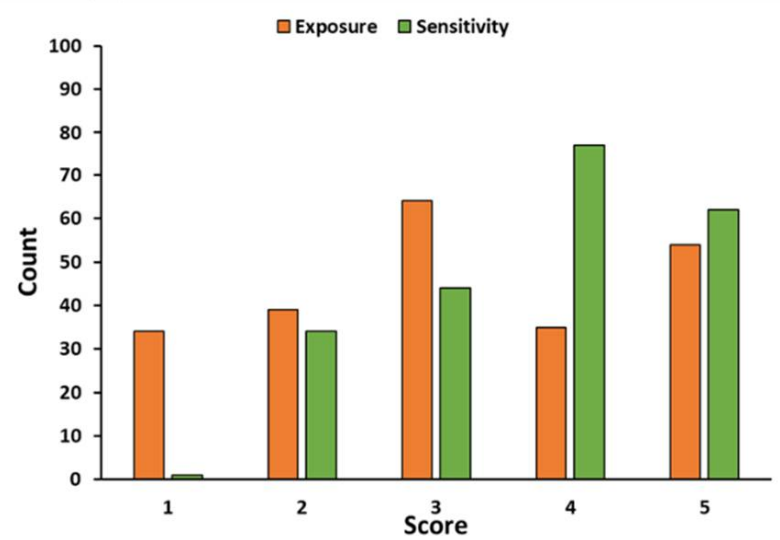

Figure 7. Distribution of exposure and sensitivity scores for selected areas in Rio Branco and Belem. The bars indicate the number of times each score was given for indicators within the exposure and sensitivity categories. (a) Rio Branco: poor area, (b) Rio Branco: rich area, (c) Belem: poor area, (d) Belem: rich area.

To explore more fully the differences between cities and areas within cities, cluster analysis was applied to the means in Table 3. The correlation coefficients for the mean indicator values are shown in Table 4. Most of the means are correlated to levels that are statistically significant. The results of the cluster analysis are shown in Figure 9. For the Exposure dimension (Figure 9a), there is no clustering of cities, but the two rich areas do emerge as a distinct cluster. Thus, richer areas have a similar pattern based on the Exposure indicators. However, for the Sensitivity dimension (Figure 9b) the main cluster which emerges is for Rio Branco (poor and rich areas). This suggests a greater degree of similarity for Sensitivity indicators within this city compared with Belem. For the Adaptation dimension (Figure 9c), there is a clear clustering into poor and rich areas, irrespective of city. Rich areas tend to do well with the Adaptation indicators while poor areas do badly, and what emerges is a clear clustering based on wealth. 
(a) Rio Branco: poor area

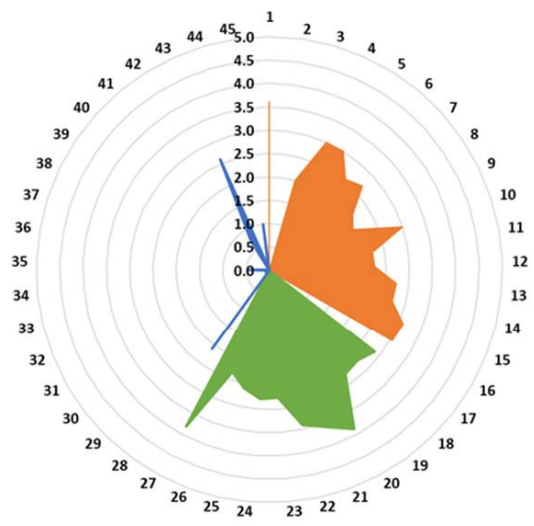

(c) Belem: poor area

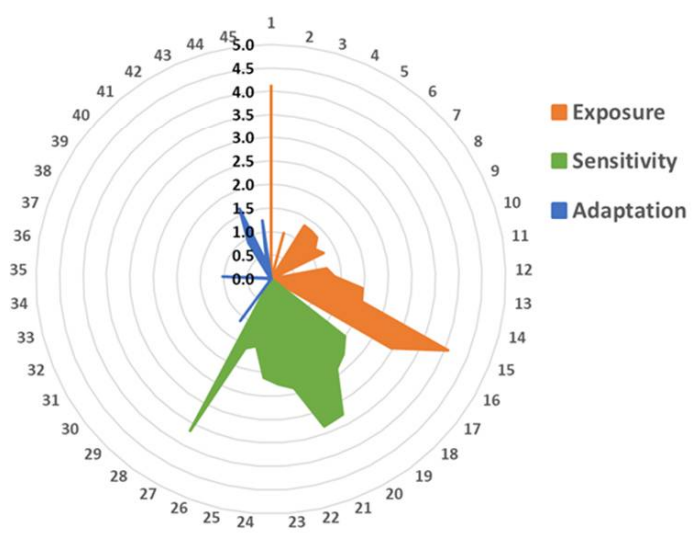

(b) Rio Branco: rich area

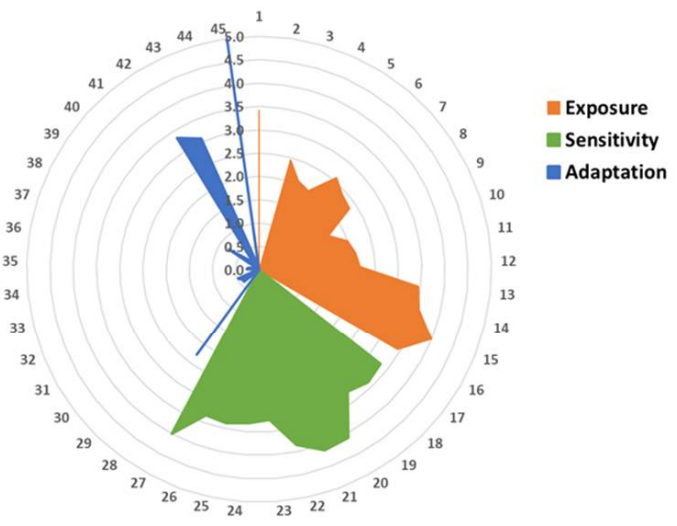

(d) Belem: rich area

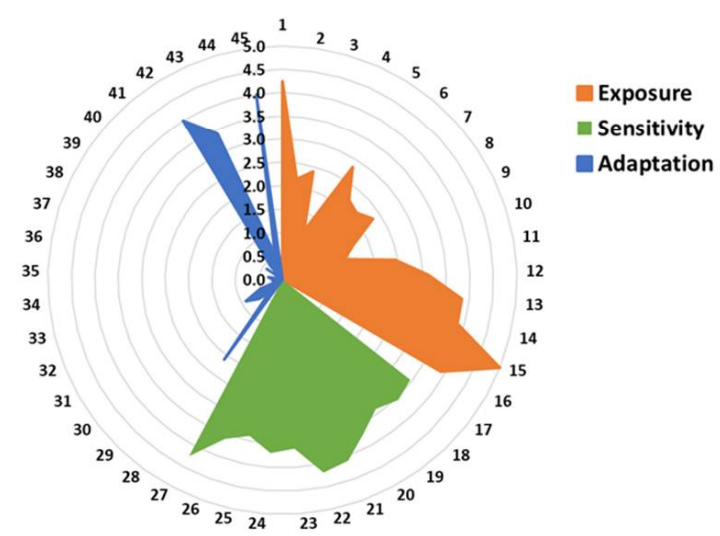

Figure 8. Radar diagrams of the mean indicator values from Table 3. (a) Rio Branco: poor area, (b) Rio Branco: rich area, (c) Belem: poor area, (d) Belem: rich area.

Table 4. Correlation coefficients between the mean indicator values shown in Table 3.

\begin{tabular}{|c|c|c|c|c|}
\hline & Rio Branco Poor & Rio Branco Rich & Belem Poor & Belem Rich \\
\hline \multicolumn{5}{|l|}{ (a) Exposure } \\
\hline Rio Branco poor & 1 & $0.52 *$ & $0.83^{* * *}$ & $0.43 \mathrm{~ns}$ \\
\hline Rio Branco rich & & 1 & $0.81^{* * *}$ & $0.89^{* * *}$ \\
\hline Belem poor & & & 1 & $0.87^{* * *}$ \\
\hline Belem rich & & & & 1 \\
\hline \multicolumn{5}{|l|}{ (b) Sensitivity } \\
\hline Rio Branco poor & 1 & $0.93^{* * *}$ & $0.92 * * *$ & $0.74^{* *}$ \\
\hline Rio Branco rich & & 1 & $0.83^{* *}$ & $0.79 * *$ \\
\hline Belem poor & & & 1 & $0.70 *$ \\
\hline Belem rich & & & & 1 \\
\hline \multicolumn{5}{|l|}{ (c) Adaptation } \\
\hline Rio Branco poor & 1 & $0.72^{* * *}$ & $0.89 * * *$ & $0.74^{* * *}$ \\
\hline Rio Branco rich & & 1 & $0.81^{* * *}$ & $0.96^{* * *}$ \\
\hline Belem poor & & & 1 & $0.82^{* * *}$ \\
\hline Belem rich & & & & 1 \\
\hline
\end{tabular}


(a) Exposure

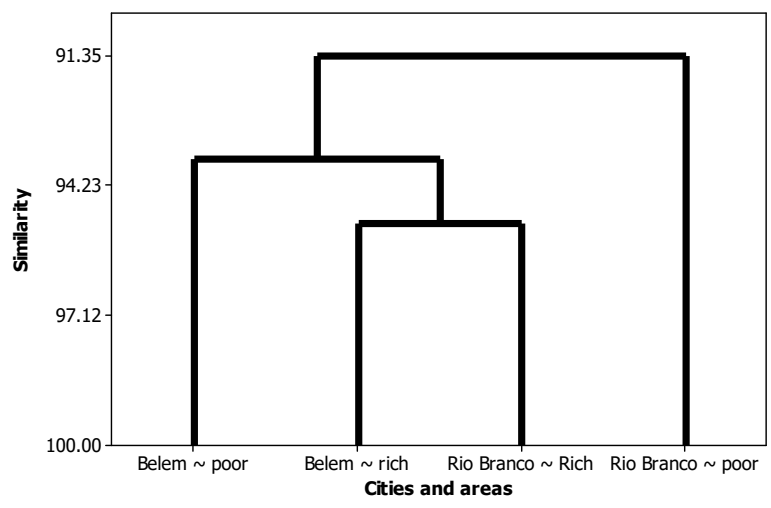

(c) Adaptation

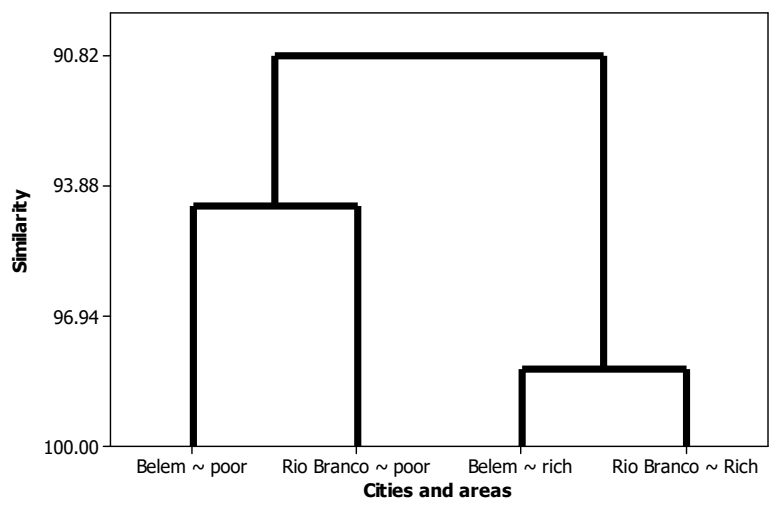

(b) Sensitivity

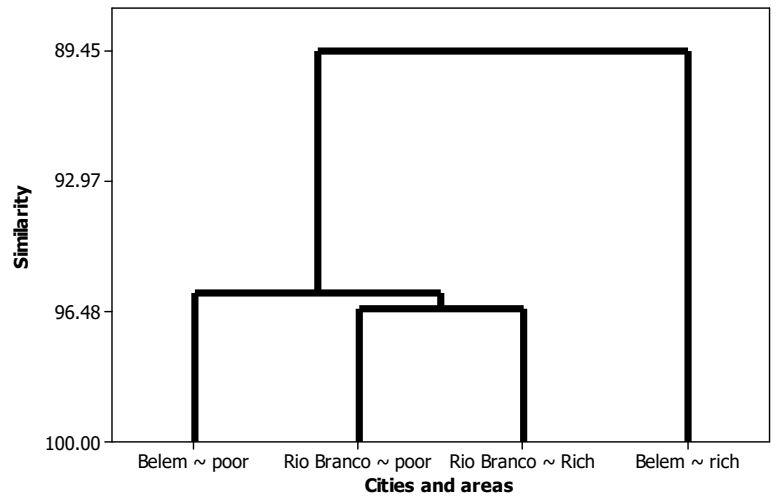

Figure 9. Cluster analysis results for the mean indicator values shown in Table 3. (a) Exposure, (b) Sensitivity, (c) Adaptation.

\section{Discussion}

This research sought to develop and apply a novel method (VIFOR) to assess the vulnerability and resilience to flooding in the urban areas of two cities in Brazilian Amazon primarily using GSV-derived observations. Based on the suite of 45 indicators spanning the dimensions of Exposure, Sensitivity, and Adaptation, it was possible to identify differences in vulnerability and resilience, and these were especially apparent in terms of differences between poorer and richer areas of the cities. Conceptualising resilience in terms of these dimensions has the advantages of being able to explore where the main contributors to resilience (or lack of it) may be coming from, and here the most noticeable differences were with the Adaptation indicators, though this was also reflected in part in the Exposure indicators. Thus, richer areas had more 'assets' that help with resilience, but some of these could themselves be vulnerable to flood damage. Poorer areas had fewer 'assets' that would help with Adaptation. Of course, as with any such framework much depends on the choice of indicators. Here, the focus was upon indicators that could be assessed visually using GSV, with some potentially also assessable via EO. This indicator set focused on a very local scale in two particular regions of two municipalities. Other indicators such as the DRIB-Index focus on the validation of disaster risk reduction models at a higher spatial scale including several municipalities. VIFOR includes a disaster risk analysis at local and microscales. However, a comparative analysis with a different geographical location including other parameters of inequality, natural biome (e.g., outside the Amazon region), or a microregion within the same city may present a different result using the same list of indicators. Regarding the validation of VIFOR and the reliability of the indicators in a different context, the availability of GSV images is obviously essential. The methodology developed here to assess the indicators from GSV imagery can help in 
providing information when data are not available (e.g., access to institutions, bureaucracy to acquire data, capability for field work and observations). The VIFOR methodology can be improved and is potentially a cost-effective method compared with the use of a field survey in areas where data are not available or for safety reasons (e.g., areas of conflicts, COVID-19 outbreak, crimes). Reasonably up-to-date GSV imagery is also needed and the VIFOR indicators have to be amenable to a visual assessment (e.g., quantity and quality of infrastructure).

Access to high resolution EO data ( $1 \mathrm{~m}$ and below) may help to capture additional features not available from GSV. Image resolution is likely to be an important factor in EO. Hence, the assessment of urban greenspace has often been a focus with GSV- and EO-based systems in urban spaces, but there are no published examples as yet of using these tools to assess vulnerability to disasters such as flooding. However, EO is also limited to populating indicators that can be passively 'seen' using visual wavelengths or the use of 'active' EO such as the use of radar. Machine learning or automatic measurements to process multiple GSV in the same location or extensive areas of the city integrated with EO time-series in real time could improve the quality of the results. The gathering of EO data with multiple tools may also enhance the VIFOR framework by using new algorithms or methods that identify key indicators of our proposed 45 indicators. In the Amazon region, one of the major challenges is to monitor the differences in vegetation and land use characteristics between each biome [39]. The National Space Research Institute of Brazil (INPE) monitors deforestation via the Amazon Deforestation Monitoring Project (PRODES), but only with a minimum unit of 6.25 ha, and it does not include some of the urban areas [39], such as the $1 \mathrm{~km}^{2}$ area of VIFOR. The improvement of remote sensing products, such as the $50 \mathrm{~cm}$ High-Resolution Planet Labs tasking provides rapid daily revisit that help to inform actions [40]. However, private high-resolution data with added value information are expensive and are not affordable to every user. Therefore, the GSV-based approach we demonstrate here provides a simple and ready-to-use tool when funding is not available to pay for the latest technology available. It requires some time and patience to monitor and measure the local area street by street, but it provides helpful information for a specific local context. Similarly, it could help urban planners and policymakers to target further investments and actions to mitigate the effects of flooding in particular streets and locations of the city.

Fundamental to prioritizing disaster mitigation efforts is quantifying flood hazard, exposure, and vulnerability [41]. EO data and remote sensing approaches can directly observe inundation [41], but there are several other indicators that affect lives and livelihoods. This study extends previous research $[17,18]$ by including an extensive list of indicators that take note of dwelling and business locations, conditions, and vulnerabilities, and locationbased general socioeconomic resilience features (e.g., observable pharmacies, community centres, etc.). VIFOR is a manual scoring process and, as such, has some limitations. For example, further research may be beneficial in order to adapt and integrate EO data to cover gaps where street view images are not available, although we expect only a subset of the 45 GSV indicators for VIFOR here to be measurable in this way. Overall, we believe that the GSV-based VIFOR approach has several strengths, notably: (i) accessibility and no cost to access GSV, (ii) possibilities to integrate and expand the research with machine learning, (iii) expandability to larger areas, and (iv) inclusion of EO data.

In addition to the selected 45 indicators included in the current VIFOR, its complementation with several other local data sources (e.g., number of health workers, doctors, crime rates) will help to better understand the trends and resilience of a particular location. Future work and new applications will be valuable to test and develop the VIFOR framework in different urban or other settings and could expand this approach further by incorporating the use of social media (e.g., Twitter, Facebook, Instagram) and high resolution EO data. 


\section{Conclusions}

This paper presents the novel Visual Indicator Framework for Resilience (VIFOR) framework based on GSV imagery to assess the vulnerability and resilience of two flood prone urban areas. The framework is useful in locations where data are not available or difficult to access from local authorities. The approach provides a valuable source of information to monitor specific visual indicators, as suggested in our list of 45 indicators.

The existing literature provides several examples of the use of GSV to assess specific indicators. The VIFOR framework extends this by leveraging easy to use and freely available GSV images to enable a multi-indicator assessment of vulnerability and resilience to flooding that is accessible to nonexperts. The framework is likely to be adaptable to several natural and other hazards according to GSV images and local geographical contexts.

Author Contributions: Conceptualization, S.M. (Stephen Morse), M.C., R.M., D.M. and S.M. (Sarah Middlemiss); methodology, M.C., S.M. (Stephen Morse), R.M., D.M. and S.M. (Sarah Middlemiss); formal analysis, M.C., S.M. and R.M.; investigation, M.C.; resources, M.C., S.M. (Stephen Morse), R.M., D.M. and S.M. (Sarah Middlemiss); data curation, M.C.; writing—original draft preparation, M.C. and S.M. (Stephen Morse); writing-review and editing, M.C., S.M. (Stephen Morse), R.M., S.M. (Sarah Middlemiss) and D.M.; supervision, S.M. (Stephen Morse) and R.M.; project administration, R.M. and S.M. (Sarah Middlemiss); funding acquisition, R.M., S.M. (Stephen Morse) and S.M. (Sarah Middlemiss). All authors have read and agreed to the published version of the manuscript.

Funding: The Space Research and Innovation Network for Technology (SPRINT) programme of Research England's Connected Capabilities Fund and Ecometrica Ltd., project award OW131379P2V5.

Institutional Review Board Statement: Not applicable.

Informed Consent Statement: Informed consent was obtained from all subjects involved in the study.

Data Availability Statement: Contact corresponding or University of Surrey authors.

Acknowledgments: The authors are grateful to the SPRINT programme and Ecometrica Ltd. for financial support for this research. We thank Ian James, Sprint Innovation Adviser and Entrepreneur in Residence at the University of Surrey, for his valuable advice and engagement with the project. We are also grateful to the following people and organizations in Brazil for their cooperation and engagement in exploring the cities and districts selected for the case studies: INPE, EMBRAPA, and CPRM.

Conflicts of Interest: The authors declare no conflict of interest.

\section{References}

1. World Bank Group. People in Harm's Way: Flood Exposure and Poverty in 189 Countries (English). In Policy Research Working Paper, No. WPS 9447; World Bank Group: Washington, DC, USA, 2020. Available online: http:/ / documents.worldbank.org/curated/ en/669141603288540994/People-in-Harms-Way-Flood-Exposure-and-Poverty-in-189-Countries (accessed on 25 February 2021).

2. IPCC. Special Report: Global Warming of 1.5C. In Summary for Policymakers; IPCC: Geneva, Switzerland, 2018. Available online: https:/ / www.ipcc.ch/sr15/chapter/spm/ (accessed on 25 February 2021).

3. United Nations. World Cities Report 2020: The Value of Sustainable Urbanization; UN Habitat: San Francisco, CA, USA, 2020. Available online: https:/ / unhabitat.org/wcr/ (accessed on 25 February 2021).

4. United Nations. The New Urban Agenda. Available online: https:/ / unhabitat.org/the-new-urban-agenda-illustrated (accessed on 24 February 2021).

5. World Bank. Disaster Recovery Guidance Series: Communication during Disaster Recovery; World Bank Group: Washington, DC, USA, 2020. Available online: https:/ / openknowledge.worldbank.org/handle/10986/33685 (accessed on 25 February 2021).

6. Gibb, C. A critical analysis of vulnerability. Int. J. Disaster Risk Reduction. 2018, 28, 327-334. [CrossRef]

7. UNDRR. United Nations Office for Disaster Risk Reduction. Hazard Definition and Classification Review. 2021. Available online: https: / / www.undrr.org/publication/hazard-definition-and-classification-review (accessed on 9 March 2021).

8. Chen, C.; Noble, I.; Hellmann, J.; Coffee, J.; Murillo, M.; Chawla, N. University of Notre Dame Global Adaptation Index Country Index Technical Report; ND-GAIN: South Bend, IN, USA, 2015. Available online: https://gain.nd.edu/our-work/country-index/ (accessed on 24 February 2021).

9. Chen, C.; Doherty, M.; Coffee, J.; Wong, T.; Hellmann, J. Measuring the adaptation gap: A framework for evaluating climate hazards and opportunities in urban areas. Environ. Sci. Policy 2016, 66, 403-419. [CrossRef]

10. Morse, S. The Rise and Rise of Indicators: Their History and Geography; Routledge: Abingdon, UK; New York, NY, USA, 2019. 
11. Chen, C.; Hellmann, J.; Berrang-Ford, L.; Noble, I.; Regan, P. A global assessment of adaptation investment from the perspectives of equity and efficiency. Mitig. Adapt. Strateg. Glob. Chang. 2018, 23, 101-122. [CrossRef]

12. Vivanco, M.L.; Villagrán, A.A.; Martínez, R.V. Using Social Work Interventions to Address Climate and Disaster Risks in Latin America and the Caribbean; World Bank: Washington, DC, USA, 2020. Available online: https://openknowledge.worldbank.org/handle/ 10986/34137 (accessed on 25 February 2021).

13. de Almeida, L.Q.; Welle, T.; Birkmann, J. Disaster risk indicators in Brazil: A proposal based on the world risk index. Int. J. Disaster Risk Reduct. 2016, 17, 251-272. [CrossRef]

14. Zhai, W.; Peng, Z.R. Damage assessment using Google Street View: Evidence from Hurricane Michael in Mexico Beach, Florida. Appl. Geogr. 2020, 123, 102252. [CrossRef]

15. ESA European Space Agency. Sentinel 1-Radar Vision for Copernicus. 2021. Available online: http://www.esa.int/Applications/ Observing_the_Earth/Copernicus/Sentinel-1 (accessed on 9 March 2021).

16. ESA European Space Agency. Sentinel 2. 2021. Available online: https://sentinel.esa.int/web/sentinel/missions/sentinel-2 (accessed on 9 March 2021).

17. Wang, R.; Feng, Z.; Pearce, J.; Yao, Y.; Li, X.; Liu, Y. The distribution of greenspace quantity and quality and their association with neighbourhood socioeconomic conditions in Guangzhou, China: A new approach using deep learning method and street view images. Sustain. Cities Soc. 2021, 66, 102664. [CrossRef]

18. Feldmeyer, D.; Meisch, C.; Sauter, H.; Birkmann, J. Using OpenStreetMap Data and Machine Learning to Generate Socio-Economic Indicators. ISPRS Int. J. Geo-Inf. 2020, 9, 498. [CrossRef]

19. Ki, D.; Lee, S. Analyzing the effects of Green View Index of neighborhood streets on walking time using Google Street View and deep learning. Landsc. Urban Plan. 2021, 205, 103920. [CrossRef]

20. Li, X.; Zhang, C.; Li, W.; Ricard, R.; Meng, Q.; Zhang, W. Assessing street-level urban greenery using Google Street View and a modified green view index. Urban For. Urban Green. 2015, 14, 675-685. [CrossRef]

21. Berland, A.; Lange, D.A. Google Street View shows promise for virtual street tree surveys. Urban For. Urban Green. 2017, 21, 11-15. [CrossRef]

22. Diakakis, M.; Deligiannakis, G.; Pallikarakis, A.; Skordoulis, M. Identifying elements that affect the probability of buildings to suffer flooding in urban areas using Google Street View. A case study from Athens metropolitan area in Greece. Int. J. Disaster Risk Reduct. 2017, 22, 1-9. [CrossRef]

23. Giuliani, G.; Petri, E.; Interwies, E.; Vysna, V.; Guigoz, Y.; Ray, N.; Dickie, I. Modelling Accessibility to Urban Green Areas Using Open Earth Observations Data: A Novel Approach to Support the Urban SDG in Four European Cities. Remote Sens. 2021, 13, 422. [CrossRef]

24. ND-Gain. Notre Dame Global Adaptation Initiative. 2022. Available online: https://gain.nd.edu/about/ (accessed on 8 February 2022).

25. Cardoni, A.; Zamani Noori, A.; Greco, R.; Cimellaro, G.P. Resilience assessment at the regional level using census data. Int. J. Disaster Risk Reduct. 2021, 55, 102059. [CrossRef]

26. Mees, H.; Tijhuis, N.; Dieperink, C. The effectiveness of communicative tools in addressing barriers to municipal climate change adaptation: Lessons from the Netherlands. Clim. Policy 2018, 18, 1313-1326. [CrossRef]

27. Moftakhari, H.; Shao, W.; Moradkhani, H.; AghaKouchak, A.; Sanders, B.; Matthew, R.; Jones, S.; Orbinski, J. Enabling incremental adaptation in disadvantaged communities: Polycentric governance with a focus on non-financial capital. Clim. Policy 2020, 21, 396-405. [CrossRef]

28. Almeida, L.Q.d.; Araujo, A.M.S.d.; Welle, T.; Birkmann, J. DRIB Index 2020: Validating and enhancing disaster risk indicators in Brazil. Int. J. Disaster Risk Reduct. 2020, 42, 101346. [CrossRef]

29. Mansur, A.V.; Brondizio, E.S.; Roy, S.; Soares, P.P.d.M.A.; Newton, A. Adapting to urban challenges in the Amazon: Flood risk and infrastructure deficiencies in Belém, Brazil. Reg. Environ. Chang. 2018, 18, 1411-1426. [CrossRef]

30. Debortoli, N.S.; Camarinha PI, M.; Marengo, J.A.; Rodrigues, R.R. An index of Brazil's vulnerability to expected increases in natural flash flooding and landslide disasters in the context of climate change. Nat. Hazards 2017, 86, 557-582. [CrossRef]

31. Alves, L.M.; Chadwick, R.; Moise, A.; Brown, J.; Marengo, J.A. Assessment of rainfall variability and future change in Brazil across multiple timescales. Int. J. Climatol. 2021, 41, E1875-E1888. [CrossRef]

32. de Andrade MM, N.; Szlafsztein, C.F. Vulnerability assessment including tangible and intangible components in the index composition: An Amazon case study of flooding and flash flooding. Sci. Total Environ. 2018, 630, 903-912. [CrossRef]

33. de Andrade MM, N.; Bandeira IC, N.; Fonseca DD, F.; Bezerra PE, S.; de Souza Andrade, Á.; de Oliveira, R.S. Flood risk mapping in the Amazon. In Flood Risk Management; IntechOpen: London, UK, 2017. [CrossRef]

34. Dolman, D.I.; Brown, I.F.; Anderson, L.O.; Warner, J.F.; Marchezini, V.; Santos, G.L.P. Re-thinking socio-economic impact assessments of disasters: The 2015 flood in Rio Branco, Brazilian Amazon. Int. J. Disaster Risk Reduct. 2018, 31, 212-219. [CrossRef]

35. IBGE. The Brazilian Institute of Geography and Statistics. Cidade de Rio Branco, Acre. 2021. Available online: https://cidades. ibge.gov.br/brasil/ac/rio-branco/panorama (accessed on 24 March 2021).

36. IBGE. The Brazilian Institute of Geography and Statistics. Cidade de Belem, Para. 2021. Available online: https://cidades.ibge. gov.br/brasil/pa/belem/panorama (accessed on 24 March 2021).

37. IBGE. IBGE Sai em defesa do Censo. 2021. Available online: https://agenciadenoticias.ibge.gov.br/agencia-noticias/2012 -agencia-de-noticias/noticias/30350-ibge-sai-em-defesa-do-orcamento-do-censo-2021 (accessed on 24 March 2021). 
38. Begum, R.A.; Sarkar, M.S.K.; Jaafar, A.H.; Pereira, J.J. Toward conceptual frameworks for linking disaster risk reduction and climate change adaptation. Int. J. Disaster Risk Reduct. 2014, 10, 362-373. [CrossRef]

39. Almeida, C.A.; Valeriano, D.M.; Maurano, L.; Vinhas, L.; Fonseca, L.M.G.; Silva, D.; Santos, C.P.F.; Martins, F.S.R.V.; Lara, F.C.B.; Maia, J.S.; et al. March. Deforestation Monitoring in Different Brazilian Biomes: Challenges and Lessons. In Proceedings of the 2020 IEEE Latin American GRSS \& ISPRS Remote Sensing Conference (LAGIRS), Santiago, Chile, 22-26 March 2020; pp. 357-362.

40. Planet. High-Resolution Imagery with Planet Satellite Tasking. 2021. Available online: https://www.planet.com/products/hires-monitoring / (accessed on 24 November 2021).

41. Tellman, B.; Sullivan, J.A.; Kuhn, C.; Kettner, A.J.; Doyle, C.S.; Brakenridge, G.R.; Erickson, T.A.; Slayback, D.A. Satellite imaging reveals increased proportion of population exposed to floods. Nature 2021, 596, 80-86. [CrossRef] 